\title{
Algunas consideraciones en torno a las relaciones hispano-norteamericanas en los años 50
}

\author{
FERNANDO TERMIS SOTO
}

\section{LAS RELACIONES HISPANO-NORTEAMERICANAS ENTRE 1945 $Y 1953$}

A lo largo de los ocho años que median entre el final de la Segunda Guerra mundial y la firma de los Pactos hispano-norteamericanos de 1953, tiene lugar una profunda evolución en los planteamientos de los órganos rectores de la política exterior de los Estados Unidos que afectó, para alterarla sustancialmente, a su disposición hacia el régimen español.

Esta evolución, tiene su correlato en la crisis y definitiva ruptura de la alianza de la guerra contra el Eje, consecuencia del rumbo tomado por las principales cuestiones internacionales de la postguerra -la creación de estados satélites de la Unión Soviética en Europa Oriental, la guerra civil china, la unificación y neutralización de Alemania, el Tratado de Paz con Japón, entre las más relevantes- que hicieron insalvable el foso abierto entre soviéticos y anglonorteamericanos, y que por lo demás, tuvieron la virtualidad de dar pábulo a un temor obsesivo que está en la raíz misma de la guerra fría, tanto o más que unos actos de agresión concretos ${ }^{1}$, y de crear una mentalidad en la que la desconfianza hacia las intenciones del cada vez más adversario era el principal elemento definitorio. Intenciones que terminaron por ser interpretadas como un más o menos secreto designio de expansión, reforzado además por las implicaciones ideológicas subyacentes al antagonismo Este-Oeste.

Un objetivo de primordial de la política exterior de los Estados Unidos, planteado ya antes de la finalización de la guerra y subsistente hasta

Cf.: Cocker, Christopher, Reflections on American Foreign Policy. London, Pinter Publishers, 1989. Págs. 48-49. 
aproximadamente 1946, era el de mantener la cohesión de la alianza antialemana durante tanto tiempo como fuera posible ${ }^{2}$. Sin embargo, ciertos pasos dados por la política exterior soviética - tanto como algunos pertenecientes al ámbito de la interior, tales como el ritmo y entidad de la desmovilización del ejército soviético-, fueron interpretados como sucesivas pruebas de una creciente hostilidad hacia los antiguos aliados, hasta dar lugar a que en Washington se reconsiderase la viabilidad de ese objetivo. El punto de inflexión definitivo llegó a causa del retraso en el cumplimiento de la pactada evacuación soviética del Azerbaiyán irani. A partir de ese momento, el presidente Truman se inclina ya de forma decidida por una línea de actuación más severa con la Unión Soviética, significada en primer lugar en la iniciativa de plantear dicha cuestión en el Consejo de Seguridad de la ONU. Este contexto internacional, sirvió de marco lógico para la primera decepción de las expectativas de perduración de una "entente cordiale" soviético-occidental. Decepción que se desprende del primer estudio global norteamericano - Informe Clifford-, sobre las relaciones soviético-norteamericanas, al concluir que la Unión Soviética no tenía intención de mantener en la postguerra el vigente balance de poder, ya que buscaba expandir su influencia lo más ampliamente posible, aún a costa de arriesgar una nueva guerra. El perdurable mito del expansionismo militar soviético recibía así la sanción oficial que requería para convertirse en uno de los ejes de orientación de la política exterior de los Estados Unidos durante más de cuatro décadas.

De acuerdo con Gaddis ${ }^{3}$, para afrontar lo que según este proceso se comenzaba a percibir como amenaza soviética, no se recurrió de manera inmediata a medidas de indole militar, sino que se hizo inicialmente desde una perspectiva económica: el Plan Marshall. Se trataria, según los planificadores norteamericanos, de sostener centros de poder independientes, que compartieran en lo posible con los Estados Unidos el peso de un eventual enfrentamiento con la Unión Soviética. Sólo cuando Ernest Bevin, responsable del Foreing Office británico, llevó la convicción a finales de 1947 de que los Estados Unidos no estaban haciendo un esfuerzo

\footnotetext{
2 Lo que no obstante no fue obstáculo para que los Estados Unidos adoptaran medidas enteramente inconsistentes con ese fin. Asi, por ejemplo, la finalización, de una manera bastante abrupta, de la vigencia de la Ley de Préstamo y Arriendo en el mismo momento de la rendición alemana, o la no consideración de créditos solicitados por la Unión Soviética a los Estados Unidos para la reconstrucción. Cf.: WALKER, MARTIN, The Cold War: A History, New York, Henry Holt and Co., 1994, Pág. 21.

V.: GADDIS, JOHN LEWIS, The Long Peace. Inquiries into the History of the Cold War. Oxford, Oxford University Press, 1987. Págs. 33 y ss.
} 
Algunas consideraciones en torno a las relaciones hispano-norteamericanas en...

suficiente, se planteó la necesidad de abordar también de forma abierta la perspectiva militar, circunstancia que en última instancia daría origen a la Alianza Atlántica.

Sea como fuere, resulta evidente que en ambos casos los gobernantes occidentales estaban ya pensando en términos de necesidades defensivas contra un real o ficticio enemigo exterior ya que de lo que se trataba precisamente era de compartir el peso de un enfrentamiento con la Unión Soviética, donde a su vez, no pasarian desapercibidas y sin consecuencias esas apreciaciones. Por supuesto que la ulterior constitución del Pacto Atlántico probablemente no haría sino confirmar, a los ojos de los estrategas soviéticos, lo bien fundado de sus sospechas.

De todas estas cuestiones, lo que más importa aquí es confirmar el hecho de que la escalada de la guerra fría fue una carretera de dos direcciones, es decir, que no cabe atribuir en exclusiva esa responsabilidad a una de las partes, y sí contemplarlo como resultado de una lógica que acabó estando abrumadoramente dominada por consideraciones militares, y que además partía de supuestos que la investigación histórica más reciente tiene serias dudas en ratificar, cuando no los reputa como manifiestamente falsos - a saber, la existencia de un plan soviético de expansión dispuesto a recurrir incluso a la vía armada-.

El punto en el que la militarización del escenario internacional alcanza su punto álgido, no se encontraba, en 1948-49, en Europa, sino en Extremo Oriente. Aquí, la mediación y el plan norteamericanos para reconstituir un gobierno nacional chino con un único ejército fracasaron, con el resultado de que la guerra civil entre el Partido Comunista Chino y el Kuomingtang habria de continuar hasta su consumación. La expulsión de los nacionalistas del territorio de China continental, tuvo unas consecuencias estratégicas de primer orden. Asumida ya como cosa cierta la hostilidad hacia los Estados Unidos del gobierno comunista chino, en los medios de planificación militar de ese país se consideró amenazado el primer eslabón de lo que sería conocido como su "perímetro defensivo" en el Pacífico, que no era otro que la isla de Formosa, último reducto del Kuomingtang. Declarado esto públicamente así, con la exclusión implícita del mismo de todos los territorios continentales de Asia oriental, el gobierno de Corea del Norte lo tomó como una invitación para ocupar la parte meridional de la península ${ }^{4}$, cosa que hizo en junio de 1950, con la inmediata consecuencia de declararse la guerra.

4 V.Gaddis, JOHn, L., Op. cit., Págs. 72-76. 
La reseña de estas cuestiones, se justifica sobradamente desde el momento en que esta cronología coincide, como habrá oportunidad de ver, con la cronología del acercamiento de los Estados Unidos hacia España, desde el primer ostracismo, hasta el inicio de los contactos que habrian de traducirse en los Acuerdos de 1953. En un contexto español, la evolución del panorama internacional tal y como queda apuntada, era, en algún sentido, la que más podían desear los responsables del régimen. Una evolución tal, permitia revalidar el esquema franquista de las relaciones internacionales de la postguerra, comenzando por el supuesto designio soviético de implantar la república soviética universal, tan aludida en la fraseologia de un Lequerica. De otro lado, y a pesar de la distancia geográfica, la guerra civil china no estuvo lejos de la atención de los responsables del régimen español, y ello tanto por la simpatía que despertaba la oposición activa - por armada - al comunismo encabezada por Chiang Kai-Shek, como porque el seguimiento atento de la actitud de los Estados Unidos hacia la misma se tomaba como un barómetro de la voluntad de aquel pais de resistir la "agresión comunista", lo que a su vez permitía calibrar la cotización en el mercado político de los títulos anticomunistas que el régimen esgrimía. Todo ello permitió, a los más informados de entre el personal político del franquismo de manera paradójica, asomarse al futuro con ciertas dosis de optimismo, y ello por razones obvias.

En su tesis sobre las relaciones hispano-norteamericanas ${ }^{5}$, Gilmore distingue tres fases en la política norteamericana hacia España, entre 1945 y 1953, que vienen a coincidir aproximadamente con los cambios de perspectiva de la política exterior norteamericana a nivel global. En un primer momento, entre 1945 y 1947, antes de que se solidifiquen las líneas básicas de la guerra fría, los Estados Unidos siguen la política general europea de sus aliados y de las Naciones Unidas, relegando al régimen español, y manteniendo una moderada presión, moral y política, para conseguir su colapso, evitando la guerra civil y el comunismo. Entre 1948 y 1950, coincidiendo con la emersión de la perspectiva militar, unidades de decisión claves instan a la reconsideración de esa política de ostracismo: A partir de 1950, coincidiendo con la declaración de la guerra de Corea, tiene lugar una progresiva acomodación con el régimen de Franco, culminando con la firma de los Acuerdos de 1953.

GILmORE, RILEY W., The American Foreign Policy-Making Process and the Development of a Post World War II Spanish Policy, 1945-1953. A Case Study, Ann Anbor, University Microfilm international, 1984. 
De lo anterior, cabe inferir que el cambio de política hacia España por parte de los Estados Unidos, tiene que ver con la muerte de la utopía fundacional de la ONU de arreglar los conflictos internacionales sin recurrir a la guerra, muerte sobrevenida como consecuencia del desarrollo de la guerra fría con todas sus secuelas. Los responsables de la política exterior y de defensa de los Estados Unidos, perciben como cierto, y además amenazante, el supuesto expansionismo soviético ${ }^{6}$, y en su búsqueda de aliados para afrontarlo, se encuentran en España con un régimen inmejorablemente dispuesto para tal función.

La derrota del Eje había significado la apertura de un período de relativo aislamiento del régimen franquista, dada su estrecha y abierta identificación con el mismo. Identificación que a posteriori se había intentado disfrazar con teorías como la esbozada por José María Doussinague desde la Dirección General de Política Exterior, según la cual, no habian sido una, sino tres las guerras libradas entre 1939 y 1945, a saber: la guerra entre Alemania e Italia de un lado, y los aliados occidentales de otro, en la que España ha sido estrictamente neutral; la guerra entre Alemania e Italia y la Unión Soviética, en la que España ha sido partidaria de las primeras; la guerra entre los aliados y Japón, en la que España ha sido partidaria de los angloamericanos. Pero este argumento, así como el de los aliados se habian beneficiado extraordinariamente de la neutralidad española, no impresionaron especialmente a sus principales destinatarios, aún a pesar de estar hasta cierto punto avalado por personalidades como la del embajador norteamericano Hayes. De esta manera, la política exterior española tuvo que concentrarse en asegurar, en lo que le concernía, la supervivencia del

"El "expansionismo soviético", es un concepto que desde hace algún tiempo está sometido a revisión. Asi, y por lo menos en cuanto se refiere a los comienzos de la guerra fria, en la actualidad se reconoce que en los móviles subyacentes a determinadas acciones soviéticas no habia sino temor a volver a reecontrarse con una situación parecida a la del tiempo de entreguerras, con un pais cercado por potencias hostiles. De ahi el interés soviético por una Alemania y un Japón unidos y neutralizados. Pero la persistencia occidental en incorporar Alemania al esquema defensivo occidental, y la creación de la Alianza Atlántica, hizo aparecer como necesaria una activa presencia militar soviética en el este de Europa. Stalin habia propuesto la retirada soviética de Alemania y de Polonia a cambio del desarme y neutralización de aquella, ofrecimiento declinado por los gobiernos occidentales, a intancias de los militares. Análogamente, la Unión Soviética se mostró dispuesta a aceptar la neutralización de Corea si se hacia otro tanto con Japón, pero éste era un precio que los norteamericanos tampoco estaban dispuestos a pagar, pues Japón se habia constituido en pieza fundamental del aludido perimetro defensivo. Por fin, la OTAN es presentada desde su fundación como un seguro contra la amenaza soviética. Como esa amenaza era, para los soviéticos, inexistente, y además tenian la certeza de que los occidentales eran conscientes de que tal amenaza no existía, ello les indujo a buscar una intención oculta en las motivaciones occidentales y en su politica. Cf.: Kennan, George. F., Memoirs, 1950-1963. New York, Pantheon Books, 1983, y Kolko, Joyce and Gabriel, The Limits of Power, New York, Harper and Row, 1972. 
régimen frente a las presiones exteriores. Pero, eso sí, partiendo de dos certidumbres: que no se iba a producir una intervención aliada en España, circunstancia garantizada por Roosevelt en dos cartas a Franco, de 2 y 8 de noviembre de 1942, con motivo de los desembarcos en el norte de África. Garantías reiteradas por mediación del Embajador Norman Armour, en enero de $1945^{7}$, y que habría que soportar la marginación de España de todos los focos internacionales de alguna relevancia política, ya advertida por Churchill en carta dirigida a Franco a finales de 1944 y reiterada en la declaración de Postdam en julio de 1945. España fue así excluida de la Conferencia de San Francisco en junio de 1945, y consiguientemente de la ONU.

Para Juan Durá, sin embargo la actitud oficial, aunque no confesada, del Departamento de Estado hacia el régimen español, estaba tempranamente prefigurada, y desde luego excluía cualquier eventualidad de desestabilizarlo: It was clear to officials like Hull and Philips democratic Spain represented political turmoil and economic chaos; working class unrest threatened to trigger a revolutionary procss and irresponsible leftist elements provided the concept of an anticapitalist "democracy" which for Hull and Philips was inconsistent with their idea of real "democracy" ${ }^{8}$. De acuerdo con esta línea argumental, el régimen de Franco pudo disfrutar, más que sufrir, un cierto "ostracismo protector", tendente a evitar que un proceso revolucionario de consecuencias indeseables, pero fácilmente previsibles, pusiera en peligro los intereses de los Estados Unidos en la Península Ibérica, y aún en Europa. Una desestabilización de España, podía dar lugar a reabrir la guerra civil, hecho que podia poner a soviéticos y anglonorteamericanos apoyando a bandos diferentes. El ya señalado interés de estos de mantener la alianza antialemana, aconsejaba alejar esa posibilidad cuanto fuera posible. El reverso de esta estrategia, consistía en demostrar públicamente a los aliados occidentales y a una opinión pública propia fuertemente sensibilizada, que el gobierno norteamericano estaba plenamente empeñado en promover el reemplazo del régimen de Franco ${ }^{9}$.

Del lado soviético, la permanencia del régimen de Franco no carecía de ventajas: su fácil desestabilización aguardaba el momento apropiado para

Presidencia del Gobierno-Archivo de Jefatura del Estado (PG-AJE), leg. 5. Conversación del señor Doussinague con el Embajador de los Estados Unidos. Madrid, 9 de enero de 1945.

\& DuRA, JUAN, United States Policy toward Dictatorship and Democracy in Spain, 1936-1953. A Case Study in the Realities of Policy Fomation, Ann Arbor, University Microfilms International, 1979. Pág. 8.

9 DURA, Juan, Op. cit., pág. 87. 
que una coalición antifascista encabezada o bien penetrada por los comunistas, pudiera acceder al poder en España. Por otra parte, la existencia del régimen de Franco dificultaba, al extremo de impedirla, la integración española en el bloque militar ocidental, además de servir como recurso propagandístico para desmentir el argumento occidental de «servir a la causa de la democracia".

Lejos por tanto de quemarse todos los puentes entre Washington y Madrid, Franco mostró la suficiente flexibilidad -en ello le iban muchas cosas- para anudar, en lo que podía, sus lazos con sus aliados, incluso cuando la guerra estaba por finalizar. Lequerica, siendo Ministro de Asuntos Exteriores, ya trató con el Embajador Hayes la posibilidad de llegar a un entendimiento político, económico y militar, ofrecimiento inicialmente rechazado, pero que progresaria, por lo menos en el aspecto militar, con la firma de los acuerdos ATC de marzo de 1945, según los cuales, se concedian al Air Transport Command norteamericano ciertas facilidades de aterrizaje y sobrevuelo de territorio español.

A lo largo de 1946, se suceden las declaraciones condenatorias del régimen: resolución de 9 de febrero en la ONU, nota tripartita anglo-franconorteamericana de 3 de abril, y resolución de la Asamblea General de la ONU aconsejando la retirada de embajadores de Madrid. Pero a tenor de lo anteriormente expuesto, esto es lo más lejos a lo que se va a llegar. Además, el régimen iba a poder contar con la ventaja que suponía el hecho de que desde 1947 la cuestión española desapareciese del primer plano de la opinión pública mundial, siendo reemplazada por las crisis griega y china, y el deterioro de la situación internacional en Europa Occidental.

El escaso margen de maniobra en el exterior, no impide a los responsables del régimen emprender una política de "revoco de fachada", en expresión de Antonio Marquina, que tiene por objeto suprimir los aspectos que en mayor medida permitían identificarlo con los preexistentes en Alemania e Italia. Es ésta una iniciativa meramente cosmética, destinada al consumo de las cancillerias extranjeras, que apenas fueron engañadas sobre su significado real en tanto que la esencia misma del régimen permanecía básicamente invariable. Política de gestos, en definitiva, que pusiera de reiieve la no peligrosidad del régimen español, y su deseo de mantener unas buenas relaciones con los aliados. Dentro de la misma, se inscribian acciones como la entrega de Laval a las autoridades francesas, el desalojo inmediato de Tánger a requerimiento aliado, etc., y a nivel interno, la sustitución de Lequerica por Martín Artajo en el Ministerio de Asuntos Exteriores, la 
promulgación de las leyes de Bases de Política Local, de Referéndum, y de Sucesión ${ }^{10}$.

A medio plazo, la defensa del régimen de los ataques procedentes del exterior descansaron en una política, en cuya formulación tuvo una especial responsabilidad Carrero Blanco " , de "dignidad y espera", incidiendo en los perfiles anticomunistas y católicos del mismo, así como en las supuestas injusticias de que es objeto España, urdidas por sus enemigos, en la línea de una profundamente arraigada concepción de la política, compartida tanto por éste como por Franco, basada en la certidumbre de la existencia de una conspiración, de dimensiones fabulosas, empeñada en mantener a España en un estado de decadencia permanente.

Que el optimismo de los responables de la política exterior del régimen no era sin fundamento, es algo que se hizo evidente a la vuelta de unos pocos años. El desencuentro entre soviéticos y norteamericanos induce una revalorización en el Pentágono del territorio español, desde un punto de vista estratégico. Directamente relacionado con ello, se encuentra el hecho de que los Estados Unidos sigan una cada vez más independiente política con respecto a España y su régimen, arrumbando la coordinación de momentos anteriores con la de Gran Bretaña. Después de declararse la guerra de Corea, el cambio en esto, como en tantas otras cuestiones, es definitivo.

Diversos factores, desde el año 1947, apuntan a una mejora de las perspectivas internacionales del régimen. Así, la firma del acuerdo entre España, Francia, Gran Bretaña y Estados Unidos para la liquidación de los bienes alemanes en España; la intensificación de los contactos con funcionarios de los Estados Unidos -y en este punto hay que señalar la conversión del Encargado de Negocios norteamericano en Madrid, Paul T. Culbertson ${ }^{12}$-; el informe de Kennan, a la sazón Director del Policy Planning Staff, constatando el hecho de que la política de ostracismo no había servido sino para afianzar la posición del régimen; la comprobación de que el comercio norteamericano con España había disminuido en torno a un $25 \%$ entre 1946 y 1948 como consecuencia del relativo aislamiento

10 V.: Portero, Florentino, Franco aislado. Politica exterior española, 1945-1950, Madrid, Aguilar, 1989.

$"$ V.: Tusell, Javier, Carrero. La eminencia gris del régimen de Franco, Madrid, Temas de Hoy, 1993. Págs. 114 y ss.

12 PG-AJE, leg. 12. Extracto de la entrevista con B. celebrada por el Sr. Subsecretario, en su despacho el dia 2 de octubre de 1947. También recogida en Pollack. Benny. The Paradox of Spanish Foreign Policy. Spanish international Relations from Franco to Democracy, London, Pinter Publishers, 1987. Pag. 40. 
económico; el voto de los Estados Unidos en noviembre de 1947 contra la renovación de la resolución de condena de España en la ONU del año anterior; la aprobación por Truman de una propuesta del National Security Council para la normalización de relaciones políticas y económicas con España y dos meses después, la indicación del Secretario de Marina, Forrestal, al Joint Command of Staff sobre la conveniencia de disponer de bases en España, entre otros países ${ }^{13}$... En adelante, contactos oficiales $u$ oficiosos de miembros del Congreso (comenzando por el Senador Gurney en septiembre de 1948), agentes del Pentágono, etc., se encargarían de allanar el camino Washington-Madrid. Incluso la enmienda O'Konski, presentada en la Cámara de Representantes al European Recovery Program Act en el verano de 1948, aunque derrotada, abriría la larga cadena de enmiendas encaminadas a dotar a España de la ayuda económica de los Estados Unidos, y que acabaría prevalenciendo con la enmienda McCarran de agosto de 1950, ni dos meses después de desencadenarse la guerra en Corea.

La llegada a Washington de José Félix de Lequerica como «inspector de embajadas" en 1948, contribuyó a potenciar la apertura iniciada en el año anterior. Los militares norteamericanos, proveyeron la opinión experta, encubriendo bajo tecnicismos su contribución a borrar la memoria de todas las condenas en la ONU y todas las declaraciones de funcionarios norteamericanos, incluido el Presidente, dictadas contra el régimen en momento anteriores. El abogado y lobbysta contratado por la Embajada de España Charles P. Clark, y Lequerica, aportaron la propaganda, y finalmente el Senador Pat McCarran, proporcionó el liderazgo requerido en un Congreso que habria de servir de instrumento para proporcionar una política de acomodación con España ${ }^{14}$. Ni las reticencias con respecto a la cuestión religiosa dentro de España del Presidente Truman, devoto baptista y grado 33 de la masonería, fueron un obstáculo insalvable para la rehabilitación del régimen.

La guerra de Corea, termina por eliminar todos los obstáculos serios que dificultaban una ayuda sistemática a España. McCarran, logra hacer pasar su enmienda al General Appropiations Bill de 1951 en agosto del año anterior, soslayando el posible veto presidencial. Ya en el verano de 1949 y en la primavera de 1950, habia intentado incluir a España en los presupuestos del European Recovery Program, pero entonces sin éxito.

\footnotetext{
13 Cf.: Marquina, Antonio, España en la politica de seguridad occidental, 1939-1986, Madrid, Ediciones Ejército, 1986. Pág. 151 y ss.

14 Gilmore, RLley W., Ob. cit., pág. 185.
} 
Ahora, McCarran conseguiría un crédito de 100 millones de dólares, reducidos después a 62,5 en la sesión conjunta del Congreso, procedentes del Export-Import Bank y a administrar por la Mutual Security Agency al margen del ERP. Tanto éste, como posteriores créditos, estarian vinculados a la cooperación por parte de España en el ámbito militar, razón por la cual estos 62,5 millones estarían bloqueados durante muchos meses, tanto por la falta de voluntad de Truman de confirmarlos, como por la demora en encarrilar las negociaciones militares para el establecimiento de bases norteamericanas en España.

\section{EL ESQUEMA FRANQUISTA DE LAS RELACIONES INTERNACIONALES EN LA POSTGUERRA}

El desenlace de la Segunda Guerra Mundial, si bien habia inducido un cambio en ciertos signos externos del régimen que influian negativamente en la imagen que proyectaba hacia el exterior, así como la reconsideración de ciertos objetivos de la política exterior -la obligada renuncia a cualquier proyecto de expansión colonial más o menos serio-, no cambió de manera importante las ideas que sobre las relaciones internacionales albergaban los dirigentes del régimen. Ideas configuradas a partir de la experiencia de la guerra civil, y del contacto con el fascismo italiano y el nazismo alemán, que venían a sedimentarse sobre el ya muy conservador sustrato ideológico característico de las élites económicas, política y miltares de la Restauración, de las que procedian en gran medida ${ }^{15}$, y que por lo demás a menudo emanaban de categorías absolutas vinculadas a creencias pseudorreligiosas -el tema de la cruzada contra el comunismo, por ejemplo-, verdaderos tópicos en los que se basaba toda una visión del mundo escasamente compartida más allá de las propias fronteras, y que muy difícilmente se dejaba moldear por la experiencia en sí.

Elemento central de este conjunto de convicciones, es la que pone como motor de las relaciones internacionales durante la guerra fría, en un sentido amplio, al expansionismo soviético, al que se atribuye la virtualidad de estar en el fondo de todos los procesos contrarios a los intereses occidentales del mundo desde 1945 -e incluso antes-, comenzando por el

15. Sobre este particular, véase: Espadas Buagos, ManuEl, Franquismo y politica exterior, Madrid, Rialp. A título de ejemplo, cabe señalar la conexión existente entre un principalísimo inspirador de la política exterior del régimen, Carrero Blanco, y el teórico del tradicionalismo español, Vázquez de Mella, señalada por Javier TuSELL, ob. cit., págs. 18-19 y 371. 
de descolonización, y terminando por el movimiento pacifista de las últimas décadas de la guerra fria.

La década de los cincuenta es un período en el que el anticomunismo del régimen español mantiene todavía un alto grado de beligerancia, al sumarse las razones de oportunidad a las intrínsecas que por su misma naturaleza le asistian. Y ello porque durante su primera mitad lo va a hacer valer como instrumento de su rehabilitación internacional en el lugar del que debía necesariamente de partir, esto es, en los Estados Unidos. De ahi que las comunicaciones entre la embajada de Washington y el Ministerio de Asuntos Exteriores faciliten una visión razonablemente aproximada de las concepciones que sobre las relaciones internacionales tenía la diplomacia española, o cuando menos, algunos de sus más directos protagonistas, al tener que pugnar con intereses y puntos de vista distintos, y aún contrarios, a los españoles, para influir en una dirección u otra sobre el Departamento de Estado norteamericano. En este sentido, los informes que, en forma de telegrama (aunque muchas veces de telegrama sólo quedara el nombre), regularmente enviaba al Ministerio el embajador en Washington resultan ser del mayor interés para conocer el desarrollo de esa pugna por la orientación de la política exterior de los Estados Unidos -en lo que podía ser objetivamente influida--, y su significado para el régimen español. En ellos, y amparados en la confidencialidad o el secreto de la comunicación, se reflejaban los puntos de vista más profundos sobre la política norteamericana de los que estaban encargados de aportar los elementos esenciales de juicio para la formulación de la política española hacia los Estados Unidos. De entre todos ellos, destacan las comunicaciones enviadas por Lequerica, fuertemente cargadas de juicios, y aún de prejuicios, que ponen bien a las claras su concepción de las relaciones internacionales durante los primeros años de la guerra fría. Admitiendo no obstante que ésta podía no ser unánime y enteramente compartida, el mero hecho de su continuidad en el puesto durante más de seis años, y su posterior promoción a procurador y vicepresidente primero de las Cortes, y embajador español en las Naciones Unidas, permiten suponer que tendrían amplio eco y aceptación entre sus inmediatos superiores, Martín Artajo, y sobre todo Franco, quien desde luego estaba al corriente de todos los acontecimientos de relevancia en los Estados Unidos por este canal, tal y como lo demuestra el que en el archivo de Jefatura del Estado se conserven numerosos despachos firmados por el embajador y ex-ministro. Abundando en esta cuestión, en ese mismo archivo se encuentran traducciones de artículos procedentes de revistas británicas y norteamericanas que presumiblemente servirian para la información del Jefe del Estado, que hacen una descripción de la situación internacional 
sustancialmente concordante con la que llegaba desde Washington de la mano del embajador.

De acuerdo con estas y otras fuentes diplomáticas españolas ${ }^{16}$ el punto central de las relaciones internacionales después de la Segunda Guerra Mundial, es el fortalecimiento de la Unión Soviética, y su negativa a llegar a cualquier tipo de arreglo para una paz real y duradera, que perjudicaría el completo programa de expansión a nivel mundial que tiene en marcha, cuya finalidad última sería la implantación de una Gran República Soviética Universal, con centro en Moscú. El mensaje dirigido por Franco a Churchill en octubre de 1944, tendría así el objeto de apercibirle de esta amenaza, y que no obstante ser ignorado, tendría la virtud de adelantarse en dos años al discurso de Fulton, en el que admitió la positiva existencia de una amenaza soviética para el mundo occidental. Por lo demás, dicho mensaje sirvió después para que la propaganda del régimen lanzara la idea de que la OTAN originalmente habia sido nada menos que un ofrecimiento de Franco rehusado en su momento por el primer ministro británico.

Como consecuencia de una guerra provocada por ella misma, y en conexión con lo precedente, a la Unión Soviética se habría anexionado, de un modo u otro, vastos territorios en Europa oriental, en tanto que en Asia, la derrota de Chiang Kai-Shek, abandonado a su suerte por los anglo-norteamericanos a pesar del hecho de que fue una vez considerado como uno de los "grandes", habría situado casi la entera inmensa área de China en las manos del comunista Mao Tse-Tung. En Malasia, Borneo y en las Indias Holandesas, el marcado movimiento antiblanco de independencia originado por la ocupación japonesa, ha sido después aprovechado por el marxismo para sus propios fines. Por lo que concierne a los aspectos económicos de la realidad mundial, ha sido necesario oponer un Plan Marshall al Plan Stalin, basado éste en la esperanza de que una Europa exhausta se convertiría al comunismo. La reacción de Stalin habría sido la de activar a través del Cominform las quintas columnas comunistas que el liberalismo gobernante había permitido desarrollarse en Europa occidental, con el resultado de huelgas, levantamientos, inestabilidad y ausencia de autoridad, sus males congénitos,

- Los tópicos de la politica exterior española pueden encontrarse en COSA, JUAN DE LA (pseud. Luis Carrero Blanco) Comentarios de un español. Las tribulaciones de Don Prudencio. Valencia. 1949, y del mismo autor, La gran baza soviética, Valencia, 1949. Un documento propagandistico redactado en ingles con el titulo de East and West, sin fechar y sin firma, pero conteniendo unas buenas dosis de la inefable ironia de Lequerica, resume bien la visión del estado de las relaciones internacionales de los funcionarios del régimen español. Puede consultarse en $A G A-A E, 8446$. 
que neutralizaron los efectos beneficiosos de los dólares norteamericanos, particularmente porque fueron destinados a financiar el déficit acumulado por los experimentos marxistas ensayados en Francia, en Inglaterra y en Italia.

Dentro el bloque occidental, la superioridad económica, tecnológica y moral de los Estados Unidos, justifica que sea este pais el que dirija la coalición contra el expansionismo soviético. Sin embargo, esa dirección se encuentra condicionada por la divergencia de intereses dentro de los países occidentales, que tiene su manifestación más importante en la política francobritánica destinada a restaurar el equilibrio de poder en el continente europeo como fórmula de apaciguamiento de la Unión Soviética, y su consecuencia más grave en el mantenimiento de una Alemania desarmada e imposibilitada para cumplir con su función de dique de contención de la inevitable marcha de las divisiones soviéticas sobre Europa occidental en un futuro más o menos próximo. Franceses y británicos, están asi empeñados en alcanzar algún tipo de modus vivendi a nivel global, que defina claramente las áreas de influencia de cada uno de estos países. Política pues de conciliación con la Unión Soviética en las antípodas de la voluntad española de oponerse al comunismo sin excluir ningún medio -incluso el armado-, que procuran hacer prosperar en los medios norteamiericanos apoyándose en la izquierda universal, induigente con el programa de expansión comunista, y su enorme influencia en la política exterior de los Estados Unidos.

De todo lo anterior, se desprende una idea fundamental, y que interesa mucho resaltar a la propaganda del régimen español: los dirigentes de la Unión Soviética son los responsables, en mayor o menor medida, de prácticamente todos los males que han afligido a Europa desde 1917, incluido el crack de 1929, el desencadenamiento de la Segunda Guerra Mundial y, por supuesto, la guerra civil española. Tan interesada atribución de responsabilidades, tiene claramente por objeto destacar la actitud antisoviética del régimen español en un momento propicio, y al mismo tiempo justificar su propia existencia cumpliendo asi, desde un plano teórico, la ya señalada función de la política exterior española de servir como instrumento para la supervivencia del régimen. Esfuerzo cuyo éxito cabe relativizar, en tanto que su perduración se consiguió más por la fuerza de circunstancias, sobre las que el mismo tenia escaso o nulo control, que por los poco plausibles argumentos esgrimidos por sus responsables, de forma que el contexto internacional hizo preferiblemente para quien tenía la posibilidad de influir en los asuntos españoles - a saber, los Estados Unidos de acuerdo con sus aliados - que no fuese alterada la estabilidad política española. 
Precisamente, la influencia anglofrancesa en la política de los Estados Unidos es uno de los temas más frecuentemente abordados por Lequerica. Según el mismo, la acción de Gran Bretaña y Francia excedería lo que razonablemente se pcdría llamar influencia, para pasar a ser una auténtica lucha por el control de la política exterior norteamericana, en orden a orientarla en un sentido más conveniente para sus intereses. Lucha sostenida entre el conglomerado espiritual inglés-izquierdista norteamericano-filo-ruso y en último término, francés, sólidamente implantado en el Departamento de Estado, y hostil a cualquier campaña anticomunista, y los elementos de orden y morales, que se encuentran fundamentalmente en ambas cámaras del Congreso norteamericano, exponentes al fin y al cabo de la vieja honestidad norteamericana y del recelo contra la monserga ideológica de los grandes periódicos israelitas y de todas las agencias de influencia británica y rusa ${ }^{17}$. Transposición, en último término de la lucha contra la opinión del pueblo norteamericano - presentada por la opinión del Congreso, particularmente cuando adopta resoluciones favorables a España-, y en favor de su oligarquia pro inglesa -triunfante, no me canso de repetirlo, en la declaración de otras dos guerras antipopulares- ${ }^{18}$.

Siendo Estados Unidos el país clave de la alianza occidental, es en Washington donde corresponde llevar adelante la política de rehabilitación internacional de España y su régimen, labor que no obstante tiene que superar ingentes obstáculos, de los que no es el menor la poco positiva actitud inglesa, máxime cuano se llega incluso a atribuir a los ingleses la capacidad de poner y quitar presidentes casi a voluntad -ahi estaría como ejemplo el caso de Taft, eliminado por ellos de la carrera electoral hacia la presidencia ${ }^{19}-$, y aún cuando Lequerica reconoce que España no está en condiciones de ejercer una influencia, ni a nivel de altos responsables políticos ni de opinión pública, equiparable en intensidad a la que despliegan franceses y británicos con los ingentes medios económicos y de relación de que disponen, si puede operar, mediante senadores y representantes amigos, en el Congreso, reivindicando el papel que España puede desempeñar en la defensa de Occidente, como un fin en sí mismo, pero también como una forma de reintroducir a España en la comunidad internacional, logrando por añadidura su rehabilitación económica. De ahi

17 PG-AJE, leg. 16. Telegrama enteramente secreto $n^{\circ} 104.14$ de abril de 1953.

18 PG-AJE, leg. 17. Telegrama enteramente secreto $n^{\circ} 118.2$ de junio de 1953.

19 PG-AJE, leg. 16. Telegrama enteramente secreto $n^{\circ} 109.13$ de mayo de 1953, y PG-AJE, leg. 17. Telegrama enteramente secreto $n^{0}$ 108. 2 de junio de 1953. 
la necesidade de llevar a cabo una acción constante en las cámaras, aspecto éste en el que insistiría una y otra vez en sus comunicaciones a Madrid, como acompañamiento de sus angustiosas peticiones de dinero para sostener el tinglado de relaciones públicas montado en torno a sí mismo y al abogado de culturales Charles $\mathrm{P}$. Clark. Por supuesto que a favor de la política norteamericana del régimen español opera el acrisolado historial de oposición al comunismo, que junto con la situación geográfica de la Península, debe hacer valer para alcanzar el puesto que le corresponde en el mundo. No en vano, España cuenta con la invalorable experiencia de haber sufrido una guerra civil de la que cabe enteramente hacer responsables al comunismo y a la Unión Soviética. $Y$ en esto reside precisamente el valor de la alianza con España: su experiencia directa de lo que es el comunismo, es el fundamento mismo de su determinación a combatirlo por cualesquiera que sean los medios - ahi está la división Azul para demostrarlo-. España es por todo esto una inversión segura en materia de defensa, pues no mantiene una actitud ambigua en cuanto a la necesidad de contener al comunismo, como los paises donde gobiernan los partidos socialistas, ni su sistema político está minado por poderosos partidos comunistas, como ocurre en Italia o Francia.

Pero precisamente por ello, España tiene que pagar el precio de los prejuicios ideológicos y el fanatismo de los más influyentes elementos norteamericanos, en tanto que para conseguir la asistencia económica necesaria para la reconstrucción, los paises receptores de la ayuda han tenido que plegarse, de grado o por fuerza, a las exigencias políticas de los Estados Unidos: asi Italia, Alemania y Francia, esta última poniendo en peligro incluso la resistencia al comunismo. España, por su parte, ha sabido mantener un equilibrio entre ambas opciones, consiguiendo al final una moderada amistad y ayuda norteamericanas, pero ahorrándose el perpetuo conflicto en que viven los paises que hacen concesiones al comunismo, permitiéndole subsistir en su seno ${ }^{20}$. Reconocimiento explícito de que la ayuda norteamericana tiene un coste a pagar por los receptores de la misma, que contrasta con sus reiteradas quejas, de entonces y de después, de la parquedad de la recibida por España, por no hacer mención de la situación del régimen en el plano internacional, tras una rehabilitación impulsada por los Estados Unidos, pero llena de condicionamientos, tras el ostracismo, consecuencia de un interés estrictamente estratégico, probada la insolubilidad del sistema político español en la comunidad internacional de la postguerra.

20 PG-AJE, leg. 19. Telegrama D VE P sin número. 1 de abril de 1954. 


\section{LA AYUDA NORTEAMERICANA A ESPAÑA}

La ayuda norteamericana a España, refleja netamente las vicisitudes por las que pasaron las relaciones bilateral. Excluida España del Plan Marshall por sus propios beneficiarios, tal exclusión sería en años posteriores esgrimida por las autoridades españolas para justificar nuevas asignaciones de ayuda, al caducar la proyectada con motivo de los Acuerdos de 1953.

Tras la primera iniciativa del senador McCarran en 1949, una segunda, coincidente con los primeros momentos de la crisis de Corea, conseguiría en definitiva sesenta y dos millones y medio de dólares, pero la iniciativa de Truman la reduciría a un préstamo a título oneroso a administrar por el Export-Import Bank, subrayando que no tenía obligación de ponerla en práctica y que el dinero sólo se facilitaría cuando sirviese a los intereses de la política exterior de los Estados Unidos. El 10 de octubre de 1951, a continuación de aprobarse la Mutual Security Act, el representante William Green propuso la concesión de doscientos millones de dólares a España, reducidos a cien en la mutual Security Appropiations Act promulgada por el presidente el día 31, y que, en su parte referente a España, dejaba la concesión a la discreción presidencial, dentro del marco de la Economic Cooperation Act de 1948 y la Mutual Security Act de 1951. Al discutirse el presupuesto para el año fiscal 1952-1953, se planteó el problema de los cien millones concebidos el año anterior y no autorizados. El 8 de mayo, las comisiones de Exteriores de ambas cámaras aprobaron su prórroga hasta el 30 de junio de 1953 asignando además una nueva cantidad de veinticinco millones de dólares para ayuda militar y técnica. Los ciento veinticinco millones quedaron incluidos en la ley finalmente refrendada por el presidente del 20 de junio de 1952. Pero básicamente el mismo argumento utilizado por Truman en 1950, sirvió para congelar estas nuevas y viejas - cantidades, bajo el pretexto de que no habian concluido las negociaciones militares, comenzadas en abril. No obstante, en el debate presupuestario de los fondos de ayuda exterior fue la propia Administración la que incluyó los ciento veinticinco millones además de hacer partícipe a España de los setecientos millones de dólares presupuestados para la construcción de bases por todo el mundo.

La nueva administración Eisenhower, no varió la política de ayuda a España, haciéndola depender de la conclusión de los Acuerdos en vía de negociación. La comisión de relaciones exteriores del Senado aprobó, además de la actualización de los ciento veinticinco millones, la adición de ciento un millones, noventa y uno para ayuda militar y diez para ayuda económica. Poco antes de firmarse los Convenios, mediante un canje de notas, la Administración norteamericana puso de manifiesto su intención de facilitar 
una ayuda a España por valor de 465 millones de dólares, en un programa que se extendia hasta el año fiscal 1956-1957, y que incluirían los 226 asignados desde 1951. Diversas razones aconsejaron, sin embargo, la prolongación de la ayuda económica hasta más allá del umbral previsto de 1957, fundamentalmente la insistencia española en la insuficiencia de la ayuda recibida, y a medio plazo, el progresivo deterioro de la situación económica de España, que hizo temer incluso la parición de un clima revolucionario, con la consiguiente amenaza a los derechos adquiridos sobre las instalaciones militares ${ }^{21}$. Desde los primeros meses de 1954, Lequerica ya se refiere a la primera de estas cuestiones, y en 1956 Artajo lo haría saber directamente a los responsables norteamericanos en el curso de su visita a los Estados Unidos del mes de abril. El general Fernández Longoria comunicaria a Areilza las consideraciones españolas con respecto a la ayuda, afirmando que era muy reducida, comparada con la dada a otros paises, e insuficiente en relación con las necesidades creadas por el Convenio Defensivo, que convertía a España en beligerante, requiriéndole un ejército imposible de organizar con los créditos asignados; incompleta, en tanto se limitaba al concepto de Military Assistance y la pequeña cantidad de Offshore Procurement, sin concederse ninguna ayuda, aunque había sido solicitada, por los conceptos Direct Forces Support, Facilities Assistance y Mutual Weapons Development; existía un criterio restrictivo en su aplicación, especialmente en la disponibilidad del contravalor de créditos en dólares, así de ayuda económica como de excedentes agrícolas ${ }^{22}$. A estas consideraciones, Areilza habría de responder señalando la naturaleza inconexa de las peticiones españolas: las quejas de la escasa ayuda americana, podian estar fundadas, pero si por un lado la argumentación del precio que pagaba España por las bases es correcta - y ese precio implicaba poner en peligro Madrid, Barcelona, Zaragoza y Sevilla-, se necesitaba una petición clara y argumentada de ayuda, lo que no había sido el caso hasta la fecha. Areilza mostraba no tener dudas respecto al carácter de quid pro quo que tenía la

\footnotetext{
21 Esta circunstancia, sumada al interés norteamericano en conseguir una apertura de la economia española a la inversión extranjera, hicieron de los Estados Unidos principal patrocinador del Plan de Estabilizacion de 1959. Algun autor ha afirmado, verosimilmente, que sin el auxilio politico y financiero de los Estados Unidos, hubiera sido improbable que España hubiera podido participar en el FMl y otras agencias relacionadas con el Plan de Estabilización, asi como que a lo largo del periodo de 1956-1959, los Estados Unidos tuvieron un papel primordial, y quizás indispensable, en el mantenimiento de la economia española a flote. WhITAKER ARTHUR, P., Spain and the Defense of the West. Ally and Liability, New York, Harper and Brothers, 1961.

22 Arhivo del Ministerio de Asuntos Exteriores, Dirección General de América del Norte (AMAE, D.G., Amér.), R-3.599/1. Carta de Francisco Fernández Longoria a José María de Areilza. 7 de marzo de 1956.
} 
ayuda, al afirmar que mayor cooperación, requería también mayor copromiso ulterior ${ }^{23}$. En el Ministerio, el plantemiento de la cuestión difería del que hacia el embajador, en tanto que se trataria no tanto de presentar unas peticiones concretas, sino de hacer una exposición franca de nuestros puntos de vista para contribuir a un estudio de la cuestión con mayores elementos de juicio, a fin de establecer un plan de ayuda militar bien definido, con objeto de que las fuerzas armadas españolas puedan estar en condiciones de cumplir las misiones que tendrian a su cargo en caso de una agresión soviética ${ }^{24}$.

Artajo sería más explícito en un artículo publicado en $1958^{25}$, afirmando que la ayuda se habia quedado corta, dada la nueva situación creada, en lo militar, por la aparición de la bomba de hidrógeno y de los proyectiles dirigidos de gran alcance, y en lo económico, por el ritmo creciente del resurgimiento español, que exigía mayor contribución del extranjero al estar superada la capacidad de capitalización del país. La ayuda norteamericana, continuaba, debía haber sido para España lo más parecido al Plan Marshall del que no participó, a pesar de tener tantos o más títulos para hacerlo que cualquier otro país. Contrariamente, ni su escasa cuantía, ni su composición, predominantemente bienes de consumo, habrían servido para lograr una producción de acuerdo con sus necesidades. En definitiva, pues, se hacía necesario aproximar el carácter de la ayuda norteamericana a lo que fue el Plan Marshall a las demás naciones europeas.

Las quejas españolas sobre la insuficiencia de la ayuda dieron lugar a sucesivos acuerdos sobre excedentes agrícolas. En abril de 1955, se firmó un «Acuerdo sobre Productos Agrícolas Excedentarios» que, con la finalidad declarada de fomentar su desarrollo económico, disponía la concesión por los Estados Unidos de un crédito de 10,5 millones de dólares para su adquisición por España. En el artículo segundo, se prevía que las pesetas producidas por las ventas, en diversa cuantía servirian para sufragar gastos de los Estados Unidos en España (9,5 millones de dólares), para la compra de materiales estratégicos destinados a las reservas de los Estados Unidos (1 millón de dólares), en tanto que para préstamos destinados a favorecer el comercio multilateral y el desarrollo económico se destinaba una cantidad indeterminada ${ }^{26}$.

23 AmAE, D.G., Amér., R-3.599/1. Carta de Areliza a Martin Artajo. 7 de marzo de 1956.

24 AMAE, D.G., Amér., R-12.028/1. Desarrollo de los convenios hispano-norteamericanos de 1953.

25 Martin Artajo, Alberto, "El primer lustro de los Convenios hispano-norteamericanos", Revista de Estudios Políticos, 98, marzo-abril 1958. Págs. 5-18.

26 AMAE, D.G., Politica Exterior (Pol. Ext.), R-5.520/3. Acuerdo sobre Productos Agricolas Excedentes entre España y Estados Unidos. 20 de abril de 1955. 
La mecánica seguida en el acuerdo es interesante, porque ilustra la manera en que los Estados Unidos convertían sus productos agrícolas excedentarios de inversiones defensivas, soslayando la demanda española de inversiones de capital. España compra, y consecuentemente Estados Unidos se deshace, de dichos productos agrícolas, transacción que produce una acumulación de pesetas que a su vez sirven para establecer un crédito a devolver por España en dólares, en tanto que el pagaré que firma el tomador español del empréstito es en esa moneda.

El ministerio de Asuntos Exteriores, recogiendo cifras norteamericanas ${ }^{27}$, daba una cifra para la ayuda norteamericana de 1.711,3 millones de dólares entre 1945 y 1962, desglosándose en 504 millones en concepto de ayuda económica (Defense Support), 25 millones del Fondo de Desarrolio Económico (D.L.F.), 504,7 millones del acuerdo sobre excedentes agrícolas (Public Law 480), 230,1 millones en créditos del Eximbank, 500 millones en ayuda militar, y 172,3 millones en donativos por casos de emergencia y de entidades privadas ${ }^{28}$.

Otras quejas españolas que se sumaban a las de la escasa cuantía e inadecuación, se referian a que las actividades de los Estados Unidos eran las responsables de la inflación en España. Tal afirmación contradecía la hecha por Franco en el discurso de presentación de los convenios a las Cortes, en el que aseguraba que los fines a que estos créditos han de dedicarse, el vacio que en la economía española vienen a llenar y la vigilancia que sobre las inversiones ha de mantenerse ofrecen plena garantía de que están eliminados los riesgos de una inflación. Además, se acusaba a los Estados Unidos de estar colocando sus excedentes de algodón en España como ayuda, pero con la intención en última instancia de ahogar el renacimiento algodonero en España. Se trataba, en definitiva, de hacer responsables de la mala situación económica a los norteamericanos, eludiendo así ante la opinión pública española una responsabilidad derivada de los propios errores.

El mecanismo de distribución de la ayuda, resultó un factor esencial en cuanto a su repercusión en la economía española, tanto o más que el monto total de la misma. Importantes partidas, como la de la ayuda militar, escapaban del control de la administración española, en tanto que se componía

27 El punto de vista español fue siempre el de excluir de la ayuda económica los créditos del Development Loan Fund, los acuerdos sobre excedentes agrícolas y los créditos del Eximbank, dado que se trataba en todos estos casos de operaciones bancarias con interés, así como los donativos para casos de emergencia y los de entidades privadas como Cáritas.

${ }^{28}$ AMAE, D.G. Amér., R-12.028/2. 
de material de guerra valorado unilateralmente por los norteamericanos. En la utilización de los créditos bancarios, la morosidad del procedimiento burocrático del Eximbank, y las propias dificultades que se encontraban en España para llevar a cabo cualquier proyecto industrial, impidieron también un mejor rendimiento de los mismos: en algunas ocasiones, las trabas administrativas para la importación de bienes de equipo hicieron preferible para las empresas españolas solicitar la importación de materias primas, como carbón, cuya remisión sí era inmediata ${ }^{29}$.

Desde una perspectiva histórica, se ha estimado de forma contradictoria el valor cualitativo de la ayuda norteamericana. Así, se ha señalado que su importancia residió más en haber sido el medio de incorporar a España al sistema económico occidental que en su volumen real, de manera que la prosperidad económica resultante de la liberalización económica transformó España en el sentido de hacer de un país subdesarrollado a comienzos de los años cincuenta, uno industrializado a comienzos de los setenta. Pero no terminarian ahi las consecuencias, sino que excederian lo puramente económico para afectar también a la esfera de lo político, al crear las precondiciones para una eventual liberalización política después de la muerte de Franco ${ }^{30}$. Desde otro punto de vista, y atendiendo de forma particular a la composición de la ayuda, se ha afirmado que ni sirvió para impulsar ni para crear una economía fuerte, como ocurrió en el caso de Europa Occidental y el Plan Marshall, sino sólo para mejorar la falta de comestibles y aliviar la balanza de pagos. Lo que desde luego si habría creado sería una fuerte dependencia del régimen de Franco de la ayuda económica norteamericana, cumpliendo así los fines específicos para los que, de manera general, estaba concebida: ayudar a proseguir la política de los Estados Unidos; facilitar la vigencia de la política de puerta abiertas con respecto al libre acceso a las fuentes de materias primas, comercio e inversión; asegurar que el desarrollo económico en el exterior estaba firmemente enraizado en la política económica del capitalismo; obtener beneficios económicos inmediatos para las compañías de Estados Unidos, buscando oportunidades para el comercio y la inversión; hacer de los receptores de la ayuda dependientes de los Estados Unidos en medida creciente ${ }^{31}$.

De otro lado, argumentos como los de Martín Artajo daban armas a la oposición antifranquista para denunciar el carácter de los convenios. Las

AmAE, D.G., Amér., R-3.594/8.

Weeks, Stanley Byron, ob. cit., Pág. 142.

Durá, Juan, ob. cit. Pág. 339. Vazouez Montalban, Manuel, La penetración americana en España, Madrid, Cuadernos para el Diálogo, 1974. Pág. 141. 
demandas de una mayor ayuda, hechas en función de un aumento de los riesgos asumidos por España revelaba, contra lo proclamado por la propaganda dei régimen, que los convenios no constituian un pacto defensivo o alianza, sino un contrato de prestación de servicios, por un lado, y de remuneración del servicio por otro. A tenor de todo ello, la oposición al régimen podia razonar que, si a más peligro se reclamaba más remuneración, el gobierno pasaba a convertirse en un mero empresario capitalizador de los peligros a que él mismo exponía a los españoles, en tanto que les negaba la capacidad de decidir tal y como hacian otros pueblos ${ }^{32}$.

\section{LA POLITICA EXTERIOR DE LA ADMINISTRACIÓN EISENHOWER Y ESPAÑA}

Con el cambio de la Administración Truman a la de Eisenhower, tuvo lugar una reorientación de la política exterior norteamericana, tanto en su fundamentación teórica como en su práctica. Así, en contra de lo que hasta entonces había sido tradicional, sus actos de gobierno no serían justificados más en razón de principios ético-morales, sino en razón del propio interés, el enlightened self-interest que Eisenhower y el Partido Republicano habian tomado como divisa para su programa de política exterior. Acciones como la intervención en Corea, se fundamentarían de este modo en la proximidad de Japón, y el peligro de que el arhipiélago cayera en manos soviéticas, y no en la necesidad de sancionar una agresión. Los disturbios en África, Próximo Oriente y América del Sur, son explicados en términos de manejos comunistas, sin mencionar los temas tan sobados del colonialismo, del nacionalismo y de la desigualdad económica ${ }^{33}$. En la misma línea, la apelación al contribuyente americano para que financie el mejoramiento material de medio universo, se basa en que ello revertirá en su propio beneficio material, y no por razones de indole moral.

Si lo anterior no alteró de manera inmediata el curso de las relaciones de los Estados Unidos con España -excepción hecha del desbloqueo en la negociación de los Convenios-, si permitió una mayor identificación del régimen español con algunos de sus aspectos esenciales ${ }^{34}$. La adopción

32 El Socialista, 20 de febrero de 1958.

3: AMAE, D.G. Amér., R-3.188/14. 31 de enero de 1953.

34 Si por parte de los diplomáticos españoles habia alguna reserva a un documento básico como la declaración hecha por John Foster Dultes ante el Council on Foreign Relations el 12 de enero de 1954 sobre la política exterior de la Administración Eisenhower, tenia que ver más con la existencia de voluntad para poneria en práctica que con su contenido. Al comentar las aclaraciones de Dulles a su propio discurso, en las que apuntaba que a pesar de todo cabía que en el 
de una política estable de contención, en tanto que se mostraba más agresivamente empeñada (al menos verbalmente) en contener el comunismo, y la renuncia a toda una serie de consideraciones de índole ética y moral para llevar a cabo ese objetivo, eran vistos con viva simpatía por el gobierno español y habrian de facilitar en el futuro la fluidez y regularización de los contactos con el régimen. En este sentido, durante la Administración de Eisenhower, éste y Dulles establecieron lo que acabaría siendo una costumbre en las administraciones republicanas, incluir Madrid en los puntos de paso del presidente y el secretario de Estado después de cada reunión de la OTAN en París. Más aún, la visita del Presidente en diciembre de 1959 excedió en su cordialidad todos los protocolos reservados para los contactos con los dictadores latinoamericanos. Por contra, los presidentes y secretarios de Estado demócratas fueron bastante más avaros en sus visitas a España, refractarios como eran a establecer asociaciones gratuitas con el régimen español ${ }^{35}$.

En el terreno de lo concreto, la actuación de la nueva Administración republicana en Corea es objeto de particular atención, en tanto que es uno de los primeros campos de aplicación de las nuevas teorías. Lo que no ha cambiado sin embargo, es la percepción del embajador español del asunto coreano, a mediados de 1953, como una faceta más de la disputa entre dos tendencias contrapuestas en el seno de la Administración norteamericana. Considerando el contenido de la campaña electoral de Eisenhower en lo referente a la política exterior, basado en la denuncia de los abandonos asiáticos de la Administración Truman-Acheson, Lequerica contempla alarmado lo que supone influencia británica en el Departamento de Estado, cuando Dulles, de forma oficiosa, hace una primera propuesta de arreglo: dos meses largos de ocupar el poder una Administración oficialmente hostil a su pensamiento y el Secretario de Estado, en formas casi no disimuladas, muestra ya su conformidad con

futuro hubiera retrocesos "para la causa de la libertad", el encargado de negocios Eduardo Propper del Caliejón observaba que ésta puede ser la puerta de escape para no verse comprometido a llevar a cabo cuanto se afirma en estos momentos. Telegrama $n^{\circ} 24.13$ de enero de 1954. Archivo General de la Administración-Asuntos Exteriores (AGA-AE), 8631.

${ }^{35}$ Afírmación que es válida dentro de ciertos límites, pues los demócratas no dejaron de cometer extraordinarias torpezas, de cara a la opinión liberal internacional, en sus relaciones con el régimen de Franco. Hacia el fin de 1961, Kennedy, de visita en Venezuela, decia a una masiva audiencia: Freedom from dictatorship and freeedom from the bonds of social and economic injustice must be the contribution of our generation... Simultaneamente, el Secretario de Estado Dean Rusk visitaba a Franco en Madrid, ensalzando el papel del régimen español como aliado de los Estados Unidos contra el comunismo. Más adelante, la visita de Adlai E. Stevenson casi coincidió con la ejecución en abril de 1963 de Julián Grimau. De hecho, con sus declaraciones, parecía alentar al régimen: Spain is the country (...) wich / found the most signs of progress and prosperity... 
ese aspecto esencial de la política británica contra la opinión del Parlamento y de los electores de su partido ${ }^{36}$, que seria la de impulsar la distensión mediante la liquidación de la guerra de Corea, perpetuando la división del país. En el otro lado, el Congreso sería, una vez más, el núcleo de la oposición a la que entiende como política conciliadora con los comunistas. A mitad de camino, el presidente Eisenhower debe mantener un difícil equilibrio entre las medidas propuestas por miembros de su propio partido, como Taft o Knowland, dispuestos a arriesgar si es necesario una nueva guerra, y los partidarios del apaciguamiento, que le impulsan a prescindir del partido mismo. Se trataría en definitiva, según Lequerica, de conseguir un arreglo con la Unión Soviética que devolviera al mundo a la situación de 1945 , con todas sus implicaciones estratégicas.

La noticia del armisticio de Panmunjom es tratada por el embajador, con poco menos que consternación, como la victoria de la política británica en Estados Unidos, de la que afirma nada menos que se propone romper el bloque anticomunista en el mundo, hacer la paz con Rusia y compartir la hegemonía europea entre el imperio soviético y el más o menos llamable imperio británico con su apéndice Francia ${ }^{37}$. Las causas que la explican, están en buena parte relacionadas con el coste electoral que para un congreso sometido a la renovación períodica hubiera tenido una firme oposición a la repatriación del contingente norteamericano en Corea, medida siempre popular. Por otra parte, el armisticio no sería sino una transacción con los soviéticos, en la que los occidentales habrian accedido al propósito, compartido por lo menos por los franceses, de impedir el verdadero rearme de Alemania, que en realidad es la auténtica cuestión central de las relaciones internacionales del momento, en la medida en que la guerra fría tiene su principal frente en Europa.

En este punto, la evidente anglofobia de Lequerica alcanza una de sus cimas, asimilando a Churchill a la categoría de verdadero aliado de la Unión Soviética, y situando enfrente de tal coalición a todo el conjunto de estados conservadores de Europa y Asia. En relación a España, una vez más, afirma que la hostilidad británica a los acuerdos con los Estados Unidos procede en primer término de la política conciliatoria mantenida con la Unión Soviética, pero también de ver su peso estratégico reducido por la anulación del valor militar de Gibraltar. Es de esperar por tanto quie

36 PG-AJE, leg. 16. Telegrama enteramente secreto $n^{\circ} 104.14$ de abril de 1953.

37 PG-AJE, leg. 17. Telegrama enteramente secreto $n^{0} 119.11$ de junio de 1953. 
continúe la acción perturbadora de Inglaterra, directamente o por intermediación de sus agentes conscientes o inconscientes en la propia España, ya desplegada durante las negociaciones con Estados Unidos, y ahora con la finalidad última de deshacer lo convenido o minimizar su eficacia. La capacidad británica de influenciar la política exterior de los Estados Unidos permite al embajador referirse interesadamente el acuerdo como mantenido precariamente: aun siendo muy sólido, está prendido con alfileres dentro de la vida norteamericana. El patrocinio de los militares norteamericanos es según esto insuficiente, y en consecuencia necesita ser asistido de una voluntad política que sólo el Congreso puede dar. En conclusión, es preciso mantener el sólido grupo de amistades parlamentarias indispensables para la buena marcha de los acuerdos y su vigencia auténtica, necesidad subrayada con el ejemplo de China, perdida por el descuido político de quienes aqui la representaron ${ }^{38}$.

La relación detallada de lo anterior permite resaltar la imagen implícita de que los órganos de poder de los Estados Unidos son el escenario en el cual se despliega un juego de influencias contrapuestas, tendente a conseguir orientar la decisiva política exterior de los Estados Unidos. Asuntos como las críticas de la opinión liberal al senador McCarthy, por ejemplo, no serían sino uno de los frentes que despliega esa lucha ${ }^{39}$. De entre los comentarios que cabría hacer de este esquema, es de obligada referencia uno referido a la suposición sobreentendida en él de que los Estados Unidos carecen de una línea clara de política exterior que los responsables norteamericanos sean capaces de seguir, por encima de las influencias que en uno u otro sentido se puede desplegar. En relación con esto, Lequerica cae en la supervaloración, deliberada o no, de la influencia que la propia embajada y su sistema de relaciones públicas ha ejercido en la rectificación de la política inicial de los Estados Unidos con respecto a España, ignorando de manera proporcional las motivaciones de orden interno que la propia Administración norteamericana hu-

38 PG-AJE, leg. 18. Telegrama enteramente secreto n 152.15 de octubre de 1953.

39 PG-AJE, leg. 17. Telegrama enteramente secreto $n^{\circ} 125.25$ de junio de 1953. Funcionarios de la embajada española, no dejarian de terciar cuando más adelante se produjera la desautorización del senador por Wisconsin. Felipe Fernández Armesto, agregado de prensa y corresponsal de varios periódicos españoles bajo el pseudónimo de Augusto Assia habia hecho unas declaraciones, que la embajada se vio obligada a desautorizar, en las que atirmaba: those who saw in senator Joseph R. McCarthy a threat to American institutions were only the Communist and their protectors. The New York Times, July 25, 1954. Entre esas personas estarian Lewis W. Douglas, ex Embajador en Gran Bretaña, y Paul G. Hoffman, ex jefe de la MSA y de la Ford Foundation, durante cuyo mandato, se habrian desviado para financiar la causa comunista en los Estados Unidos millones de dólares de la misma. 
biera podido tener en variar esa política. De ahí también su insistencia en la acción continuada - se entiende: de influencia- en los órganos donde puede ser ejercida con posibilidades de éxito, el Congreso, mediante el cultivo del lobby por él creado, lo que a su vez conecta con sus angustiadas peticiones de dinero a Madrid, en orden a mantener bien engrasada la maquinaria que la hace posible. Desde Madrid, no obstante, y contrariamente a sus recomendaciones, conseguido el objetivo prioritario de establecer una conexión con los Estados Unidos a través de los Convenios, se debió de considerar que además de resultar altamente gravoso el mantenimiento de todo el sistema de relaciones públicas, la nueva situación creada permitía un contacto más directo con la Administración norteamericana, razón añadida para prescindir, en lo posible, de onerosos intermediarios, de manera que después de la firma de los mismos, la actividad del lobby español va decayendo paulatinamente hasta su total extinción en los años sesenta.

En otro orden de cosas, que el respaldo diplomático que los Estados Unidos proporcionaban al régimen español como derivación implícita de los Convenios tenía ciertos límites infranqueables, es algo que no tardó mucho en hacerse evidente para los responsables de su política exterior. Las cuestiones de Gibraltar, con la visita de la reina de Inglaterra y Marruecos, en este caso la reciente deposición de Mohamed $V$ y la entronización de ben Arafa, habian dado lugar a que las relaciones con Gran Bretaña y Francia entraran en una fase de tensión entre los últimos meses de 1953 y los primeros de 1954, reflejada en España en manifestaciones callejeras alentadas por la Falange, que llegaron incluso a producir destrozos en bienes británicos. Estos sucesos dieron lugar a una enérgica respuesta en los medios de comunicación norteamericanos, reflejada en la correspondencia de Lequerica, en la que advertía además no ya que en tales cuestiones no se podría contar con el apoyo norteamericano, sino que además se facilitaba la resurreción de un movimiento de opinión, promovido por la izquierda en conjunción con los protestantes más conservadores, contraria incluso a la ejecución de los acuerdos hispano-norteamericanos, que no podrían resistir ni los más influyentes amigos de España en Washington. Situaba en esta ocasión correctamente los términos de la cuestión al embajador al firmar que mientras España sea un país sumado a la defensa de occidente contra la barbarie soviética y sin dificultades con las otras naciones europeas más o menos empeñadas en el mismo propósito, incluso nuestro poderosos enemigos de aqui aceptan el acuerdo [...]. Pero en cuanto pueden encontrar en nosotros sintomas de descontento tipo nación de la Liga Árabe o cosas por el estilo, resucitan las viejas hostilidades y se reenciende la pasión hacia los tradicionales aliados 
Inglaterra y Francia ${ }^{40}$. A nivel oficial, de una manera más matizada el gobierno norteamericano también dio a entender que no toleraría que los ataques españoles a sus aliados francobritánicos llegaran demasiado lejos. La ocasión propicia para hacerlo fue un discurso del embajador Dunn en la Cámara de Comercio de Bilbao el 24 de febrero, aludiendo de forma enfática a la solidaridad entre Francia, Gran Bretaña y Estados Unidos en la reciente Conferencia de Berlín. Richard Mowrer, corresponsal del Christian Science Monitor, se refirió al discurso de Dunn afirmando que la parte del mismo que hacía referencia a esos países, había sido incluida deliberadamente para recordar que Britain and France are allies of the United States, that they are part of the common front opposing Soviet imperialism and that it would be a mistake to assume that America is indifferent to Spain's attacks against these two powers ${ }^{41}$. Sin duda fue éste un desenlace enormemente didáctico para el régimen, del cual no dejaria de tomar nota: la cuasi-alianza con los Estados Unidos, en modo alguno venía a mejorar las perspectivas españolas de solucionar otros problemas de su política exterior presentes o futuros, en cuanto afectaran a los intereses estratégicos de los más estrechos aliados de los Estados Unidos, y mucho menos los propios. La actitud norteamericana en la independencia de Marruecos, y posteriormente en la guerra de Ifni, por ejemplo, no sería ajena a este planteamiento, al margen de que hubiera en los Estados Unidos un amplio estado de opinión contrario a la pervivencia de las viejas formas de colonialismo. Por parte española, en años posteriores, cuando llegara la ocasión de renovar los acuerdos de 1953 en circunstancias menos satisfactorias, no se dejaria de recordar precisamente lo limitado que había resultado el respaldo norteamericano en cuestiones estimadas como de vital importancia para España.

La correspondencia de la embajada con el Ministerio de Asuntos Exteriores cambia en gran medida de tono cuando a finales de 1954 Areilza sustituye a Lequerica en Washington. A partir de ese momento, desaparecen de la misma los aspectos más ostensiblemente reaccionarios propios de la visión de las relaciones internacionales que éste reflejaba en sus escritos, y que tan a menudo recordaban discursos mucho más familiares en Europa antes de 1945. A cambio, lo que se muestran son unos juicios que resultan mucho más matizados y libres de maniqueísmo que exhibe Lequerica. A título de ejemplo, con Areilza la política interna y externa de los Estados Unidos cobra una coherencia

40 PG-AJE, leg. 19. Telegrama D VE $P n^{2}$ 206. 11 de tebrero de 1954.

4 Christian Science Monitor, March 19, 1954. 
estrictamente interna que antes estaba bien ausente, o perdida entre las brumas de los conciliábulos británicos. Esto, en la práctica supone encontrar un escenario del que han desaparecido buena parte de los actores que veíamos figurar hasta entonces. El panorama norteamericano después de las elecciones de 1954, tal y como es descrito por Areilza, se caracteriza por la postergación de los elementos más radicales de ambos partidos demócrata y republicano, en una aparente superación de los períodos de aplastante mayoría de un partido sobre otro propios de los anteriores sesenta o setenta años. De hecho, la orientación política exterior e interior de los Estados Unidos se explica a partir de la eliminación de los elementos extremistas de ambos partidos, lo que jugaría en favor del concepto de political bipartisanship, especialmente relevante en sus relaciones internacionales. A pesar de ello, Eisenhower habría conseguido mantener la unidad dentro del partido republicano, en contra de la urgencia con que el ala liberal del mismo le incitaba a prescindir de los McCarthy y Knowland, pero reduciéndola a una minoria manejable cuando poco tiempo atrás era la fracción más fuerte. La experiencia demuestra, contra la opinión que manifestaba Lequerica, que los moderados han alcanzado su éxito sobre una base electoral, al ser derrotados en las elecciones candidatos derechistas en estados normalmente republicanos, en tanto que candidatos republicanos moderados triunfaron en otros de mayor tradición demócrata. En política exterior, ha sido doblemente necesaria la cautela, ya que mientras en realidad se seguía la línea trazada por Truman-Acheson, para aplacar a la derecha ha sido necesario emplear un lenguaje más agresivo que la acción que se pensaba seguir.

El curso de la política internacional en los años cincuenta, dio lugar a que en las relaciones entre España y los Estados Unidos la cuestión de los esfuerzos para el mantenimiento de la paz fuera un tema abordado con relativa frecuencia en las conversaciones bilaterales. En este punto, y habida cuenta de que la supuesta amenaza soviética sobre Occidente era la piedra angular sobre la que el régimen hacía descansar su política exterior (sea cual fuere el significado del concepto aplicado al régimen de Franco), no extrañará que desde el ministerio de Asuntos Exteriores se mostrara siempre una radical desconfianza hacia toda iniciativa que pretendiera llevar adelante planes dirigidos a formalizar un arreglo pacífico de la guerra fría, y que supusieran la subsistencia indefinida de la Unión Soviética como estado de inspiración comunista. Actitud procedente del convencimiento de que, cualesquiera que fuesen los medios a utilizar, los dirigientes comunistas soviéticos no renunciarian nunca al programa de expansión que les era atribuido. Cuestión al margen, era la creencia de 
que en el fondo la ideología comunista no era sino una cobertura extremadamente útil para lo que ni más ni menos era el secular imperialismo ruso. De manera análoga a lo que ocurriera en los tiempos de la Revolución Francesa, cuando Francia soslayó la imposibilidad física de mantener dominada a toda Europa mediante la divulgación de sus principios a través de las campañas napoleónicas, una Rusia agotada habria de permitir en el futuro la independencia nominal de los países que permanecían bajo su ocupación, pero a cambio de la formación de gobiernos comunistas ${ }^{42}$.

La muerte de Stalin en marzo de 1953, y el proceso político desarrollado en la Unión Soviética a continuación hasta la estabilización de la autoridad de Kruschev, no varió un ápice las apreciaciones de fondo de las autoridades españolas. Consideraban sin embargo que la desaparición de aquél había abierto una crisis política, que se sumaba a la economia, y que junto a la gran inferioridad en armamento -en contra de lo que afirmaban-, les ponian en una situación de gran debilidad. Fruto de esa debilidad seria el deseo de los dirigentes soviéticos de alcanzar un acuerdo político y militar que permitiera la superación de la guerra fría, que desde España se ve como el intento de ganar tiempo para superar esa desventaja -compartiendo el mismo argumento que públicamente empleaban el Pentágono y un Congreso de mayoría demócrata desde noviembre de 1954-. Que los gobiernos occidentales se presten a ese juego, es aceptable desde el punto de vista de que no se podrían negar a participar en cualquier iniciativa que tuviera por objeto la conclusión de la paz, pero $\sin$ llevar demasiado lejos la confianza en los resultados que por esa via se pudieran obtener. En el fondo de este planteamiento, se puede encontrar un cierto temor a que un acuerdo entre Occidente y la Unión Soviética dé por concluida la guerra fría, desagradable perspectiva para el régimen que durante cierto tiempo tuvo cierta difusión en las más altas instancias de la política exterior española, a tenor de las consideraciones hechas por Areilza a Martín Artajo sobre ciertos aspectos de la realidad internacional de esos momentos:

En Extremo Oriente, los Estados Unidos han asumido el compromiso de defender Formosa, incluidas las islas de Quemoy y Matsu, y al mismo tiempo "sujetar» a Chiang Kai-Shek. Pero la presión británica ha dejado la puerta abierta a la cesión de esas islas a cambio de un armisticio. La

42 PG-AJE, leg. 23. Conversación del ministro de Asuntos Exteriores, señor Martin Artajo, con el subsecretario de Estado norteamericano para los Asuntos Europeos. 25 de julio de 1955. 
hipótesis alternativa, la guerra de Estados Unidos-China, tendría grandes ventajas para la URSS: desgaste político y económico, y aislamiento norteamericano, pudiendo contar sólo con Filipinas, Thailandia, Corea del Sur y el propio Chiang. En Europa occidental, los Estados Unidos hacen del rearme alemán la base de su defensa. Tienen enfrente, sin embargo, la política francesa y la URSS. La última, se va a emplear a fondo para impedirlo, utilizando bien sus agentes en Francia e Italia, o mejor una ofensiva de paz que, en una conferencia de alto nivel ponga fin a la ocupación de Alemania y Austria.

En los Estados Unidos, los republicanos ganarán las elecciones de 1956 con Eisenhower, dada su política de pacificación de término medio, contra el sector de opinión dentro de su propio partido encabezado por el senador Knowland. No en vano, se ha desatado una amplia campaña tendente a hacer ver la necesidad de entablar un diálogo con el bloque comunista, a fin de examinar las bases de una coexistencia, aún cuando sea temporal, si la Unión Soviética no renuncia a sus objetivos a largo alcance. Esto, para Eisenhower tiene motivos lógicos de diferente índole: políticos, pues un bienio tranquilo y sin guerras tendria enorme atracción para el electorado en las elecciones de 1956; económicos, pues las perspectivas son buenas para 1955-56 si el ambiente de paz se consolida, y además, las grandes firmas industriales desearian introducirse en los vastos mercados tras el telón de acero. Pero sobre todo, lo que hay es terror a la enorme capacidad destructiva de la bomba de hidrógeno, que teóricamente todavía podría aumentarse en millones de veces, pudiendo llegar a poner en peligro a la humanidad entera. De la experiencia de la bomba $\mathrm{H}$ participan ya norteamericanos, británicos y soviéticos. Se estima en los Estados Unidos que llevan una ventaja de tres a cinco años en todo lo concerniente a armamento atómico y en la fabricación de la bomba $\mathrm{H}$. Hay quienes suponen que la coexistencia patrocinada por la Unión Soviética, y su actitud conciliadora más reciente se debe a que no se desea arriesgar la propia existencia y la del régimen, en una guerra que podría significar la pérdida de todas las ganancias de postguerra, y que fragmentaría política, económica y socialmente el país. Esto no quiere decir que deseen verdadera paz, pero obliga al Consejo de Seguridad Nacional de Washington a tener en cuenta la posibilidad de una guerra de ese tipo. Se tiene presente también que los Estados Unidos han perdido un margen de seguridad del que disfrutaron durante ciento cincuenta años. Siendo esto así, ambas superpotencias están experimentando con la coexistencia, que es pacífica en tanto no envuelve amenaza directa de bombardeo nuclear. Si la paz precisa algo más que ese efecto negativo, es otra cuestión. En tanto, menudean los 
incidentes, y no sigue intentando debilitar las alianzas y producir defección en las coaliciones del adversario ${ }^{43}$.

Ese cuadro, puede sin embargo verse comprometido por la actitud agresiva de China comunista, en su conflicto con la China nacional. Entre esta última, y los Estados Unidos, ya se anuncia la firma de un tratado de garantías limitadas. Un clima que liquidara el problema chino y austro-alemán, daría paso a una política de generosidad económica con la Unión Soviética, ofreciéndoles apoyos ilimitados, con el fin último de abrir el vasto mercado soviético. Detrás de este propósito, estaría el $70 \%$ de la gran industria.

La aplicación de las armas nucleares a la táctica militar supone unos cambios en los ejércitos, que los Estados Unidos quieren llevar a la OTAN, en un plan de tres a cinco años y muchos miles de millones de dólares. En tanto llegan los IBM, el SAC es el encargado de la disuasión.

Las conclusiones de estas premisas, son el peligro remoto de guerra en China, de consecuencias imprevisibles, o la mayor posibilidad de alcanzar un arreglo en Asia, lo que dejaria a Chiang como aliado incómodo. Un arreglo en Asia, deseado por Gran Bretaña y Rusia, y los políticos de Washington, excepción hecha de Knowland y sus seguidores, podría a su vez traer la ofensiva de paz rusa a Europa, firmando un tratado con Alemania y Austria. Si ello ocurriera, cabría esperar que los Estados Unidos hicieran grandes concesiones a la Unión Soviética, que sacaría indudables ventajas prácticas de un arreglo de esa naturaleza, que podría romper cuando le conviniera. A su vez, los norteamericanos tendrían tiempo para reorganizar un ejército en Europa basado en las armas nucleares y los IBM.

Una evolución del panorama internacional en esa dirección, sería poco deseable desde el punto de vista español, porque reduciría el papel de España, y el valor de las bases. Areilza hace aquí unas interesantes afirmaciones, en relación con la ayuda norteamericana, que contradicen en gran medida las lanzadas para el consumo público sobre su carácter: si nos aferramos a la tesis bases por ayuda y que ésta es insuficiente, podremos encontrarnos un dia con que las bases han perdido valor, como nuestro argumento. Por añadidura, la ayuda no se prolongará mucho. Puede finalizar este año o el que viene. Vivir pendiente de la cuantia de ésta es mal sistema para hacer planes económicos. Aparte de que en

43 AMAE, D.G. Amér., R-3.594/16. Despacho reservado n 944.27 de noviembre de 1954. 
realidad, consiste en acumular miles de millones de pesetas en España a semi-disposición del gobierno norteamericano, origen de futuras discordias. La receta del embajador para evitar los males aparejados de una evolución semejante cuenta con dos componentes esenciales: el ingreso en la OTAN y la consecución de un crédito a largo plazo de los Estados Unidos. El primero de ellos, evitaría el peligro de que España llegara a ser en algún momento el "aliado incómodo", ligando su suerte de Europa entera, pero a resguardo de cualquier modificación estratégica o táctica que alterara el valor de las bases. El segundo, permitiría separar el problema comercial del político y militar, porque si esa identificación nos fue en un momento dado indispensable, puede sernos a la larga perjudicial mezclar cosas como el cambio de la peseta con la defensa del mundo libre ${ }^{44}$.

La percepción que de la evolución política y militar de la Unión Soviética tuvieron los centros de planeamiento estratégico en los años siguientes, impediria la temida devaluación del valor estratégico de España y sus bases. Las dimisiones de Mikoyan y Malenkov en febrero de 1955, serían interpretadas como el fracaso de la línea política marcada por éste último, que preveía un aumento del nivel de vida de la población incluso a costa de la industria pesada. La tendencia, pues, acaba demostrando ir en sentido contrario. De ello, según Areilza, se ha de esperar que las presiones en el Congreso norteamericano para recortar los gastos militares no sólo han de desistir, sino que estas aumentarán, en tanto que la ayuda exterior se habrá de aprobar sin tantas dificultades y reducciones como tenía planteadas. En el caso de que la Unión Soviética adopte una política más agresiva, ello dará lugar a una más estrecha identificación de los aliados con las posiciones de los Estados Unidos. Al hilo de lo anterior, el 20 de abril de 1954 Eisenhower propone el desarrollo del Mutual Security Program, como continuación del European Recovery Program. El contexto sin embargo es distinto, toda vez que se considera a las naciones europeas incluidas en el ERP suficientemente solventes como para no necesitar en lo sucesivo ayuda económica suplementaria. Respecto a España, junto con Yugoslavia y Berlín, se considera que tienen unas circunstancias particulares que aconsejan asignaciones que aseguren la continuidad de la cooperación. Finalmente, a España se adjudica para el año fiscal 1956 un grant de 50 millones de dólares en concepto de ayuda para la defensa, del que por lo menos 22 millones serán destinados a productos agrícolas.

44 Amae, D.G. Amér., R-3.599/1. Carta $n^{\circ} 29$ de Areilza a Martín Artajo. 28 de febrero de 1955. 
El norte de África era también un punto de referencia común para el régimen español y los Estados Unidos, en tanto que durante estos años el proceso de descolonización anunciaba una serie de cambios que, vistos desde la perspectiva global de la guerra fría, interesaba mantener bajo un estrecho control. Desde 1951, los Estados Unidos habían venido manteniendo alli un complejo de bases esenciales para su estrategia de cerco de la Unión Soviética. Por añadidura, se contaba con que zona norteafricana fuera una base de operaciones aliada en la contingencia de declararse una guerra general. Desde esta perspectiva, en consecuencia, resultaba de la mayor importancia el conseguir que la independencia de los países de la zona no significara la relajación de sus lazos con Occidente, circunstancia que exigia de la diplomacia norteamericana una extremada prudencia en sus tratos con estos países. Habia que contar, además, con un estado de opinión en los Estados Unidos favorable a los colonizados ${ }^{45}$, razones todas estas que inducian a la neutralidad en los conflictos coloniales en Marruecos, Argelia y Túnez.

De lado español, las dificultades en Marruecos comenzaron con el retorno del sultán Mohamed ben Yusuf en diciembre de 1954. Depuesto por los franceses y sustituido por ben Arafa en violación del Tratado de Fez y de los pactos secretos franco-españoles de 1904, la intensa campaña de los nacionalistas marroquíes en favor del sultán depuesto y de la independencia fue sostenida y alentada por el alto comisario García Valiño desde la zona española, bajo la suposición de que nada esencial podría cambiar. Pero la línea política seguida por Eisenhower en esta cuestión, a tenor de las consideraciones anteriores, se plasmó en la práctica en la recomendación a los franceses de ofrecer el autogobierno a Marruecos, sin soslayar los intereses españoles ${ }^{46}$. Paralelamente, el gobierno francés daría un giro a su política marroquí, proponiendo un fórmula de solución, basada en el concepto de "interdependencia", que daria a Marruecos la independencia, incorporándose a la Unión Francesa.

La política española quedaba así en evidencia. Franco intentaría enmendar el error afirmando que Marruecos necesitaría todavía de unos veinticinco años para estar en condiciones de acceder a la independencia. En declaraciones a la prensa norteamericana ${ }^{47}$, advertía el peligro de la influencia comunista, señalaba el interés de los Estados Unidos en que

45 AmaE, D.G. Pol. Ext.. R-3.832/11. Despachos $s / n^{2}$ de 25 de agosto y 1.400 de 14 de septiembre de 1955.

46 Marquina, Antonio, ob. cit. Págs. 699-700.

47 New York Herald Tribune, 2 de abril de 1956. 
el conflicto se resolviera de forma pacífica, y denunciaba el concepto de interdependencia bajo el que los franceses presentaban la independencia marroquí, porque suplantaba la auténtica independencia del país. Añadiria por fin que España no aceptaría la conclusión de acuerdos firmados sin su intervención.

En marzo de 1956, Marruecos consigue la independencia de Francia, a lo que García Valiño responde con un intento de independizar el califato de Tetuán que no prosperó, resultando infructuosas todas las tentativas españolas para conservar su parte del protectorado en tanto que la fuente legal del protectorado español no procedía de un tratado con los marroquies, sino del hispano-francés de 1912. Declarado por Francia el fin del protectorado, España no tenía ningún título legal para continuarlo en su zona. En consecuencia, Franco tuvo que permitir la anexión del Marruecos español ${ }^{48}$, reconocida en la declaración conjunta hispano-marroquí de 7 de abril de 1956.

Después de la independencia, Marruecos continuó siendo una fuente de inquietud para el gobierno español, que temía las posibilidades que eventualmente podrían ofrecérsele a la Unión Soviética para introducirse en esa zona geográfica. A este respecto, Martín Artajo tuvo oportunidad de entrevistarse durante su visita a Estados Unidos con el subsecretario adjunto Robert D. Murphy, para tratar esta cuestión. En ella, el ministro español señalaría el temor que producía en España la celebración de una conferencia internacional sobre el estatuto de Tánger, que daría ocasión a los soviéticos para intervenir. Sugería que los miembros del comité de control se reunieran para revisar el estatuto en ese momento, sin esperar a la fecha en que estaba previsto hacerlo, en 1957. Apuritaba también que en Marruecos habia habido dos actitudes contrapuestas, la de Francia, que había consistido en ceder con desgana tras una larga lucha, y la de España, que había ofrecido ventajas generosamente, de acuerdo con un modo de proceder mucho más conveniente. Afirmaba, por fin, que se habia entrevistado con El Fassi, del Istiqlal, que pretendía mantener la presión sobre Francia, mediante la rebelión, para forzar el cumplimiento de las promesas hechas.

A la pregunta de si existía alguna conexión entre las actividades en Marruecos y los recientes disturbios estudiantiles y huelgas, Martín Artajo contesto que las perspectivas de éxito en Marruecos de los comunistas

48 V. Shneldeman, J.L. (ed.), Spain and Franco, 1949-1959. Quest for International Acceptance. New York, Facts on File, 1973. 
descansaban en la explotación de las aspiraciones nacionalistas de independencia. Después de ésta, la alianza entre comunistas y nacionalistas cesaría, y el comunismo sería menos peligroso. Respecto a España, la influencia comunista procedía de Francia, no de Marruecos ni Ceuta o Melilla, dado que resultaba relativamente fácil cruzar la frontera. Sobre las huelgas, afirmaba no tener información, pero de acuerdo con la prensa americana (!), creía que era puramente una controversia laboral, basada en el disgusto por el reciente aumento de salarios en España. Si no había comunismo en España, era porque el gobierno no dejaba actuar a los comunistas. Al fin y al cabo, España todavía estaba en el período de postguerra de una trágica guerra civil. Finalizaba el ministro reiterando la posición española respecto a Ceuta y Melilla: ciudades españolas antes que marroquies, que nunca habian formado parte del protectorado ni del Imperio Marroquí, y cuya población era mayoritariamente española ${ }^{49}$.

Por estas fechas, se producen los primeros incidentes en Ifni, que se intensificarían en noviembre de 1957, con la ofensiva sobre posiciones españolas de un ejército aparentemente irregular. A ello se había sumado unos meses atrás el conflicto diplomático abierto por la reclamación formal del territorio por el gobierno marroquí, saldado provisionalmente con la negativa española a su entrega.

A lo largo del conflicto militar, el ejército español había dado pruebas de graves deficiencias, que venían a agregarse a la imposibilidad de utilizar el material norteamericano recibido como contrapartida a los acuerdos de 1953, por la negativa de los Estados Unidos a dar la autorización requerida. Sólo con la colaboración del ejército francés se consiguió neutralizar las fuerzas del ejército de liberación con rapidez. En el plano político, los intentos españoles de obtener el respaldo diplomático de los Estados Unidos, vinculando al ejército de liberación con la subversión comunista, fueron ineficaces. A lo más que llegaria el departamento de Estado, en un momento en que se estaba dilucidando la continuidad de las bases norteamericanas en Marruecos, sería a recomendar reiteradamente la necesidad de llegar a un acuerdo por la vía de la negociación, previniendo sobre la posibilidad de verse España envuelta en un interminable conflicto colonial en el que no tardaría en extenderse el foco de la infección comunista ${ }^{50}$. Foster Dulles, comunicó en enero de 1958 al gobierno español que recomendaría a Marruecos el cese de las hostilidades, pero

49 Amae, D.G. Amér., R-3.599/41. Resumen de la entrevista de Martín Artajo con Robert D. Murphy. 12 de abril de 1956.

50 PG-AJE, leg. 30. Carta reservada no 60 de Areilza a Castiella. 2 de diciembre de 1957. 
que por su parte debia hacer algo para que Marruecos permaneciera al lado de los países occidentales. En abril del año siguiente, tras unas conservaciones secretas en Portugal, el gobierno marroquí tomó posesión de Tarfaya. En ese mismo mes, Franco escribió una carta a Dulles en la que hacia constar su pesimismo sobre el futuro del norte de África, y manifestaba su opinión de que, a la vista de lo que ocurría en Marruecos, se hacía necesaria la permanencia de Francia en Argelia, particularmente en la base de Bizerta, al objeto de que la espalda de Europa esté asegurada. De esa manera, la cuestión quedaría recluida dentro del área de la nación francesa, pero si se trasladaba al plano internacional, caería en una esfera apta para la intervención de los soviets y de sus satélites, que arrastrarian a los países que, como desconocedores de la cuestión, no quieren ver en ella más que un problema de colonialismo [...]. Por eso yo [...] me siento alarmado por la impresión que percibo en América sobre este problema ${ }^{51}$.

Prescindiendo de otras cuestiones de orden interno español, los episodios de la independencia de Marruecos y la guerra de Ifni no pasaron sin consecuencias para las relaciones bilaterales hispano-norteamericanas. Particularmente esta última, dio lugar a un deterioro de la confianza española en el apoyo que cabía esperar de los Estados Unidos en conflictos en que éstos no estuvieran directamente implicados, al hacerse evidente la existencia de una clara escisión entre la percepción española del alcance y los métodos de las subversión comunista - que incluía conflictos del tipo colonial, como el de lfni, en el que la procedencia checa de las armas del ejército de liberación y la percibida como creciente amistad soviéticomarroquí justificaba su consideración de lucha contra el comunismo-, y la norteamericana, menos dispuesta a reconocer en este caso concreto la implicación, siquiera lejana, de la Unión Soviética. Todo ello, unido a otras cuestiones como la negativa norteamericana a reubicar las bases, las periódicas e insatisfechas peticiones de aumentar la ayuda a España, etc., fueron alimentando una cierta frustración en la diplomacia española, que si no tenía un reflejo inmediato en las relaciones bilaterales, saldría a flote a lo largo de las sucesivas negociaciones para la renovación de los Convenios en años posteriores.

Los esfuerzos norteamericanos para incluir a España en la OTAN nunca habian estado del todo ausentes en el horizonte de las relaciones bilaterales

51 AmAE, D.G. Pol. Ext., R-5.790/3. Carta de Franco a John Foster Dulles. 28 de abril de 1958. 
desde la firma de los convenios de 1953. La actitud del régimen sobre el particular tradicionalmente había consistido, con uno u otro matiz, en negar su interés en pertenecer a la alianza, considerando que los pactos bilaterales con Estados Unidos eran suficientes para asegurar la contribución española a la defensa occidental, y que había países a los que repugnaba el verse mezclados con el régimen español, por lo que España no presentaría su candidatura para ingresar en la alianza, pero sí recibiría con simpatía una invitación para integrarse ${ }^{52}$. Era en definitiva la misma actitud de digna reserva que habia dado lugar a que España no solicitara su admisión en la ONU hasta no tener una garantía fiable de que su solicitud no había de ser rechazada. Pero el régimen no podía desconocer que el hecho de permanecer al margen de la alianza le situaba en un lugar subordinado en orden a las prioridades de suministros e información. Subordinación que el gobierno español pretendió remediar proponiendo que los Estados Unidos consideraran, a todos los efectos, equiparable la prioridad de España con la de los países OTAN, propuesta que por presiones de los aliados los Estados Unidos no estaban en condiciones de cumplir.

El año 1957 sin embargo, es el momento en el que los Estados Unidos van a hacer un particular esfuerzo por lograr ese objetivo, aprovechando el ambiente favorable que parecía existir dentro de la propia Alianza Atlántica, creado a partir de una retirada parcial de fuerzas británicas de la misma. Consideraban además los militares norteamericanos que España sería una buen lugar para emplazar bases de misiles de alcance medio, no esperándose que el gobierno español pusiera impedimentos para la instalación de las bases requeridas, a la vista del creciente entendimiento entre la Unión Soviética y Marruecos. Demostrada la imposibilidad de superar el veto danés y noruego, añadido a la amenaza soviética de represalias nucleares si se llevaban a cabo tales proyectos, los Estados Unidos se decantaron por la opción de mantener un régimen estable en España, evitando la contingencia de unos disturbios previsibles dadas las crecientes dificultades que la economía española venía padeciendo, y que amenazaban con una vuelta al racionamiento de productos básicos. Para este fin, los Estados Unidos accedieron a vender a España productos agrícolas excedentarios, pagaderos en pesetas no convertibles, que por ello tendrian que ser gastadas en la propia España.

52 Véanse por ejemplo las declaraciones hechas por Martin Artajo al diario inglés The Times, aparecidas el 2 de enero de 1956. El 26 de julio del mismo año, en un articulo atribuido al general Diaz de Villegas aparecido en el diario $\mathrm{Ya}$, se afirmaba que las fuerzas aéreas estacionadas en España podrian quedar bajo el mando del cuartel general de la OTAN. 
De otro lado, la crisis del Líbano tendría repercusiones en la posición norteamerciana en el Atlántico oriental. Habiéndose negado Francia e Italia a que las bases situadas en su suelo sirvieran como punto de apoyo a la invasión de aquél país, los Estados Unidos utilizaron unilateralmente las que tenian en Marruecos, lo que dio lugar a que Mohamed $V$ exigiera su abandono. De ello resultaba un aumento del valor de las bases en España, que el gobierno español pretendió aprovechar en cuando llegase el momento de negociar la novación de los acuerdos de 1953.

\section{LOS PACTOS DE MADRID}

La importancia de los Convenios firmados el 26 de septiembre de 1953 justifica el que se le dedique un capítulo al margen de las cuestiones que se han venido tratando hasta aquí. Sin duda fueron, junto con el Concordato firmado por el régimen de Franco con el Vaticano poco antes, los dos pilares fundamentales sobre los que se basaba buena parte de su crédito político exterior, y desde luego los que de forma elocuente pusieron el techo a la integración internacional que el franquismo era capaz de lograr. Después de estos dos acuerdos con los padrinos político y espiritual, pocos éxitos más en sus relaciones internacionales pudo acreditar el régimen del general Franco, aparte del ingreso en las naciones Unidas en 1955, ya que ni siquiera toda la capacidad de influencia norteamericana pudo reducir la oposición de algunos gobiernos de Europa occidental al ingreso en la OTAN y la CEE, para los que seguía siendo, en caracterización más o menos afortunada, la misma dictadura que había sido en los momentos previos y durante la Segunda Guerra Mundial.

En este punto, se hace imprescindible recordar y comentar algunos de sus puntos principales, porque lo que aparece en ellos, tanto como lo que falta, permite delimitar su verdadero alcance, que inevitablemente ha de contrastar con las afirmaciones que los panegiristas hicieron desde el día en que fueron hechos públicos.

Los Convenios firmados el 26 de septiembre de 1953, eran en realidad tres: un Convenio relativo a la ayuda para la defensa mutua, un Convenio sobre ayuda económica, y un Convenio defensivo. Este corpus público se completaba con una serie de acuerdos técnicos y notas adicionales secretas, que le daban su auténtica dimensión, tal y como el profesor Ángel Viñas ha puesto en evidencia.

En el preámbulo del Convenio Relativo a la Ayuda para la Mutua Defensa, se recogen los motivos que justifican su conclusión. De acuerdo 
con el mismo, los gobiernos de España y Estados Unidos se proponen estimular la paz y la seguridad internacional, promover la comprensión y buena voluntad, y mantener la paz mundial. Para ello, y a la vista de la legislación promulgada por el Congreso de los Estados Unidos que permite la prestación de ayuda militar, económica y técnica a España, las partes manifiestan su deseo de establecer las obligaciones y condiciones que rigen el suministro de ayuda militar por el gobierno de Estados Unidos, asi como las medidas que cada gobierno tomará conjunta e individualmente para tales fines.

En el artículo I, se establece que cada gobierno pondrá a disposición del otro u otros que se pudieran acordar el equipo, materiales, servicios u otras asistencias que se puedan convenir. Su uso será concordante con la Carta de las Naciones Unidas, y exclusivamente para los fines de afirmación de la paz y seguridad internacionales. Su uso para fines distintos requiere el previo y mutuo consentimiento, como también lo requiere la transferencia a terceros. Se tomarán las medidas adecuadas compatibles con la seguridad para mantener informada a la opinión pública de las disposiciones de ejecución del convenio.

En el artículo $V$, ambos gobiernos se comprometen a mejorar la comprensión y buena voluntad internacionales colaborarán en el mantenimiento de la paz mundial, adoptando medidas conjuntas para eliminar las causas de tensión internacional. Particularmente, el gobierno español asume el compromiso de aportar la contribución que le permitan su potencial humano, recursos, instalaciones y condición económica general al mantenimiento y desarrollo de su poder defensivo y el del "mundo libre», tomando las medidas adecuadas para asegurar la utilización efectiva de la asistencia económica y militar proporcionada por los Estados Unidos.

En el artículo VI, España se compromete a cooperar para controlar el comercio con naciones que amenacen el mantenimiento de la paz mundial.

En el artículo VII, se establece una duración indefinida del acuerdo, hasta un año después de su denuncia por escrito una de las partes, con las salvedades que se indican.

En el espíritu de este Convenio, generalizable al conjunto, está implícita la suposición subyacente a toda doctrina militar, a saber, que la mejor fórmula para prevenir la guerra es estar preparado de la mejor forma posible para afrontarla. Desde una lógica que es intemporal, y por lo tanto tan válida para el año 1953 como para cualquir otro, resulta difícilmente conjugable la voluntad de eliminar las causas de la tensión internacional, estableciendo medidas de confianza y buena voluntad, con el hecho cierto de estar, con la misma firma del Convenio, creando un foco de tensión, 
en la medida en que el cumplimiento de los términos del mismo implicaba, desde una perspectiva soviética de la que por supuesto se prescindia, el aumento proporcional de la amenaza percibida. El resultado final era por tanto, y contra lo que se pretendía establecer, un aumento de la tensión internacional. Cuestión al margen era si la tensión añadida llevaría o no a alcanzar el punto de ruptura. En esta ocasión, evidentemente no se alcanzó, pero desde luego, el paso siguiente, que era el de incorporar España a la OTAN - y en términos militares, dicha incororación aparentemente no significaba una variación sustancial del balance estratégico con respecto a la situación creada por los Convenios-, dio lugar a serias advertencias por parte soviética de severas represalias militares que, de haberse cumplido, probablemente hubieran significado el desencadenamiento de la Tercera Guerra Mundial.

En términos menos generales, una lectura detenida del preámbulo fija también el carácter que tiene la ayuda que va a recibir España. Dicha ayuda, se recibe a cambio o como contrapartida de ciertas obligaciones que contrae la parte española, confirmando el carácter de quid pro quo que el régimen, de cara a la opinión pública, se esforzó siempre en ocultar. Respecto al preámbulo, cabe por fin señalar también el hecho de que la ayuda norteamericana estaría sujeta al control del Congreso de los Estados Unidos, mientras que las obligaciones españolas, cosa corriente en todas las dictaduras, no estaban supeditadas más que a la voluntad del gobierno, y al margen de toda fiscalización.

Respecto al artículo VI, resultaba la conformación de una medida que hacía tiempo había ya adoptado el gobierno español, la adhesión a la enmienda Kem ${ }^{53}$ en septiembre de 1951, y a su sucesora, la ley Battle. En virtud de las mismas, mientras los Estados Unidos estuvieran empeñados en hostilidades por cuenta del Consejo de Seguridad de las Naciones Unidas, no se prestaría asistencia económica ni financiera (aparte de la militar) a todo país que exportara o autorizase la exportación al bloque soviético (incluso China comunista y Corea del Norte) de armas, material militar o productos para su fabricación, que los Estados Unidos hubieran embargado por razones de seguridad nacional. La recepción de ayuda norteamericana -incluso los préstamos del Eximbank - requiere del país receptor la aceptación de la enmienda, por la que se obligaba a certificar mensualmente que no había exportado al bloque soviético ninguno de los

53 Presidencia del Gobierno-Libro Registro de la Secretaria del Consejo de Ministros (PGLRSCM). Libro I. 14 de septiembre de 1951. 
artículos previstos. Por descontado que esta disposición, de una u otra forma, habría de sobrevivir largamente a la guerra de Corea.

El contenido del preámbulo del Convenio sobre Ayuda Económica, por su parte, se comenta por sí solo, al afirmar: El Gobierno español y el Gobierno de los Estados Unidos de América: reconociendo que la libertad individual, las instituciones libres y la verdadera independencia de todos los paises, al igual que la defensa contra la agresión tiene como base principal el establecimiento de una economía sana:...

En el artículo II, el gobierno español se compromete a estabilizar su moneda, fijar o mantener un tipo de cambio real, equilibrar su presupuesto estatal tan pronto como ello sea posible, crear o mantener una estabilidad financiera interna y, en general, restaurar o mantener la confianza en sus sistema monetario; a desalentar las prácticas y arreglos de los que resulte una restricción de la producción y un aumento de los precios, o que pongan trabas al comercio internacional, a estimular la competencia y la productividad y a fomentar el comercio internacional removiendo los obstáculos que pudiera entorpecerio, cuando ello afecte a la realización del programa convenido; a concertar lo antes posible un acuerdo con el gobierno de los Estados Unidos para reglamentar para los nacionales y compañías norteamericanas un sistemas de pagos y transferencias internacionales que permita la conversión paulatina de sus saldos acumulados en pesetas.

El artículo III, establece una serie de garantías que permitan al gobierno de los Estados Unidos adquirir moneda y bienes, así como subrogarse derechos por operaciones realizadas por ciudadanos de los Estados Unidos con la aprobación del gobierno español.

Según el artículo IV, el gobierno español facilitará a los Estados Unidos la adquisición de materiales de los que éstos sean actual o potencialmente deficitarios, para la formación de stocks $u$ otros fines.

El artículo $V$, establece la fórmula según la cual el gobierno español pondrá a disposición del de los Estados Unidos la cantidad en pesetas correspondiente al $10 \%$ de la contrapartida de la ayuda necesaria para gastos administrativos, así como las cantidades necesarias señaladas por el gobierno de los Estados Unidos para gastos en pesetas relacionados con la construcción y mantenimiento de las instalaciones militares que se convengan.

Respecto al conjunto del Convenio sobre Ayuda Económica, cabe afirmar que quizás fuera éste el que tuvo, a largo plazo, una repercusión más directa sobre la vida española concebida de forma global. En él, cumpliendo el 
principio norteamericano de utilización de la ayuda exterior para abrir mercados y en línea con lo señalado más arriba, se encuentra el germen de la plena transformación económica iniciada con el Plan de Estabilización, que integró a España, ya sin los condicionamientos implícitos en la economía autárquica que por 1953 estaban todavia bien presentes, en la corriente general del mundo capitalista, si bien en una posición de neta desventaja en cuanto que a la economía española le tocaba competir con las de Europa occidental, que habian sido reconstruidas contando con los beneficios del Plan Marshall. Por añadidura, la exportación española, cualquiera que fuese su volumen y composición, tendría que introducirse en mercados que llevaban años repartidos entre los países occidentales, y a los que cada vez resultaría más difícil acceder en la medida en que éstos habían iniciado un proceso de integración que culminaría en 1957 con el Tratado de Roma, que daba origen al Mercado Común Europeo.

La garantía que se establece en el artículo III, tiene una importancia que conviene recalcar, porque dio pie a una intensificación de la penetración cultural norteamericana en España. Con motivo de este artículo, se negoció a lo largo de 1954 la adhesión de España al Informational Media Guarantee Program ${ }^{54}$. Genéricamente, según este programa, el gobierno de los Estados Unidos garantiza la convertibilidad en dólares de las divisas obtenidas por ciudadanos o empresas de ese país, que ha de ser receptor de ayuda norteamericana a través del Mutual Security Program. Las divisas así obtenidas por el gobierno de los Estados Unidos, se emplearán después en gastos derivados del mismo MSP. A través del mismo, llegarían a distribuirse en España publicaciones de masas como el Reader's Digest, Life y Time, asi como publicaciones de índole científica, que contribuirían, junto con el cine, y en la medida en que dichas publicaciones alcanzaban progresivamente mayor difusión a difundir en España el modo de vida norteamericano -y su ideología - lo que a la larga tuvo un impacto decisivo en la transformación sociológica española, especialmente visible a partir de los años 60 .

En el artículo IV, está implícito otros de los fines de la ayuda exterior dada por los Estados Unidos, el asegurarse el acceso a materias primas y materiales estratégicos. Lo cual no tiene necesariamente una implicación militar, o por lo menos no únicamente, sino que también estaría relacionada con una política que tiene como objeto último el garantizar el acceso a dichas materias primas mediante la acumulación de stocks que permitan el control de los precios internacionales, soslayando asi en su propio beneficio

54 Amae, D.G. Amér., 3.594/3. 
los efectos adversos que pudiera tener el funcionamiento de un mercado carente de esos medios de prevención. El reverso de la moneda consiste, naturalmente, en que los países productores de las materias primas se ven forzados a aceptar unos niveles de precios para su producción que actúan como un verdadero tapón para sus posibilidades de desarrollo.

Del artículo $V$, cabe mencionar la falta de correspondencia entre los porcentajes de la ayuda destinados a fines exclusivamente económicos en España, con los porcentajes para el mismo fin en otros países. Mientras en España es de un 30\%, destinándose un $60 \%$ a los gastos de construcción de la bases y un $10 \%$ a los gastos administrativos de los Estados Unidos, la norma general en casos análogos había venido siendo de un $90 \%$ destinado a inversiones directas en el pais receptor, y un $10 \%$ para gastos administrativos. La justificación que siempre esgrimió la parte norteamericana se fundamentaba en el hecho de que las bases eran de utilización conjunta, y que el mismo hecho de ser construidas ya significaba un beneficio para la economía española.

La gran ausencia del Convenio sobre Ayuda Económica es un programa concreto de prestación de la misma por parte de los Estados Unidos a España. Ausencia mediante la cual los negociadores españoles, sin duda con el superior beneplácito del Jefe del Estado, dejaban poco menos que a la buena voluntad de los poderes Ejecutivo y Legislativo de los Estados Unidos la asignación de las cantidades que había de recibir España por uno $u$ otro concepto. Si a eso se agrega el extraordinariamente alto porcentaje de la contrapartida puesta a disposición de los norteamericanos, no extrañará que, como se ha venido señalando, las quejas de los mismos que habían firmado el Convenio salieran bien pronto a la luz. Lo cual nos lleva directamente a la cuestión de porqué se firmaron unos Convenios en los que ni si quiera estaba claro que se fuera a poner a España en condiciones de defenderse a sí misma, cuestión de la que se tratará más adelante.

En el preámbulo del Convenio Defensivo se contiene su misma justificación: expresamente se advierte de la existencia de un peligro para el mundo occidental, que aunque no se menciona, no puede ser otro que la Unión Soviética. Una vez más, se alude al deseo de contribuir al mantenimiento de la paz y la seguridad internacionales mediante la adopción de medidas que contribuyan a aumentar la capacidad defensiva propia y la de las demás naciones dedicadas a los mismos fines.

En el artículo I, se señala que las eventualidades con que ambos paises pueden verse enfrentados aconsejan que por el interés de la política de defensa occidental las relaciones entre ambos paises se desenvuelvan sobre 
una base de amistad estable, basada en el apoyo por los Estados Unidos del esfuerzo defensivo español para los fines convenidos, mediante la concesión de asistencia a España en forma de material de guerra durante un período de varios años, con la posible coperación de la industria española, para contribuir en definitiva a la defensa de España en la medida que se convenga en conversaciones técnicas, a la vista de las circunstancias. Contribución condicionada por las prioridades y limitaciones derivadas de los compromisos internacionales de los Estados Unidos y de las exigencias de la situación internacional y supeditado a las concesiones de crédito por el Congreso. Como consecuencia, el gobierno español autoriza al norteamericano a desarrollar, mantener y utilizar con fines militares, juntamente con el gobierno de España instalaciones sobre territorio bajo jurisdicción española. Los Estados Unidos satisfarán las necesidades mínimas de material requeridas para la defensa del territorio español mientras se adecuan las instalaciones convenidas.

En el artículo III, se establece que las instalaciones de utilización conjunta quedarán bajo bandera y mando español. De España será también la obligación de atender a la seguridad exterior, si bien los Estados Unidos podrán ejercer vigilancia sobre el personal, instalaciones y equipo norteamericanos. El momento y la forma de utilización de las instalaciones serán fijados de mutuo acuerdo.

Según el artículo $V$, la vigencia del Convenio será de diez años después de firmado, con dos períodos de prórroga automática de cinco de no seguirse el procedimiento de cancelación.

Las alusiones contenidas en el preámbulo a terceros paises, en la práctica son una vinculación de la política defensiva española a la de todo el bloque occidental, hecho éste que los propios responsables del régimen no tendrían nunca ningún inconveniente en reconocer. Pero lo que sí se puede destacar de esta cuestión, es que los países de Europa occidental, que a efectos prácticos son los aludidos, se beneficiaban de la protección añadida que suponía la presencia norteamericana en España sin tener que pagar el precio político de la colaboración directa con el régimen español. Lo cual no impidió que a la Unión Soviética, con integración española en la OTAN o sin ella -que a estos efectos poco le había de importar, pues los bombarderos norteamericanos en cualquier caso podian despegar de bases situadas en territorio español-, se le brindase una excelente arma para desmentir las permanentes alusiones al mundo y las instituciones libres que los norteamericanos no tuvieron ningún rubor en utilizar incluso en el texto de los Convenios.

En el artículo I, se certifica oficialmente la defunción de la hacía tiempo desaparecida política de hostilidad de los Estados Unidos hacia España. 
Ello significaba en la práctica que el régimen podía contar con la amistad oficial de los Estados Unidos como elemento de estabilización interna y externa, inmunizándole contra cualquier eventual repetición de la situación internacional a la que se vio enfrentado después de la Segunda Guerra Mundial. De otro lado, y de forma análoga a lo ya dicho con respecto a la ayuda económica, difícilmente se podria haber ideado una manera más imprecisa de formular el compromiso norteamericano de suministrar ayuda militar a España, dada la inexistencia de un programa siquiera fuese mínimamente delimitado para hacerla efectiva. En cambio, y como contrapunto, sí aparece claramente el compromiso que asume la parte española, bien concretado en los acuerdos técnicos complementarios al Convenio ${ }^{55}$.

El artículo III, que prevé que el mando de las bases quedará bajo mando español, es sustancialmente vaciado de contenido por la nota adicional al párrafo segundo, según la cual, en caso de agresión comunista que amenace la seguridad de Occidente, las fuerzas norteamericanas podrán hacer uso de ellas con sólo comunicar sus propósitos. En otros casos de emergencia, el momento y el modo de utilización será objeto de consulta urgente entre ambos gobiernos, determinándose a la vista de las circunstancias. En poco quedaba por tanto el mando español, si los norteamericanos podían utilizar las bases siguiendo únicamente su propio criterio, exponiendo a España a las represalias que eventualmente pudiera lanzar el atacado. Pero no resultaba desde luego inútil en la medida en que este artículo, tal y como estaba enunciado, fue ampliamente utilizado para la justificación de la firma del conjunto.

$Y$ es que desde la perspectiva de las autoridades del régimen, el conjunto de los Convenios fueron un éxito diplomático, tanto más completo porque fue obtenido contra la oposición de poderosas influencias dentro y fuera de los Estados Unidos. En unas Consideraciones sobre los convenios entre España y los Estados Unidos y la situación de la defensa nacional ${ }^{56}$, escritas en torno al mes de febrero de 1961, Carrero expone con alguna extensión su posición -compartida sin duda en ámbitos más amplios dentro del propio Estado-con respecto a los convenios. De acuerdo con estas consideraciones, se distingue el espíritu formal de los mismos, el expresado en el preámbulo del Convenio Defensivo, con el espíritu real, cuyo origen está en una razón exclusivamente militar: la conveniencia para Estados Unidos de disponer de bases aéreas y aeronavales, para hacer

55 V. Marquina, antonio, ob. cit. Págs. 567-568, y Viñas, Ángel, ob. cit. Págs. 195-276.

56 AMAE, D.G. Amér., R-12.028/2. 
frente a una agresión soviética. El interés norteamericano, sumaba la conveniente posición geográfica, a la actitud decididamente anticomunistas $-y$ lo que no se dice, el interés del régimen por salir del aislamiento- El Péntagono obtuvo por tanto que el Gobierno de los Estados Unidos se entendieran con el gobierno español, pero en contra del ambiente político adverso a España, ambiente que los convenios no habrian conseguido deshacer, con la consecuencia de que aún entonces cabía la posibilidad de verse agravado con una nueva Administración en los Estados Unidos. Ello sería debido a la existencia de sectores políticos que, aunque anticomunistas, no veían el sistema político español con simpatía alguna, y se esfuerzan por boicotear todo lo que le es favorable, aunque revierta a su vez en su conveniencia.

A continuación, Carrero se extiende en la formulación de su teoría de las tres internacionales, la comunista, la socialista y la masónica, que pretenderían dominar el mundo ejerciendo un totalitarismo universal. Sus herramientas serían la democracia liberal basada en los partidos políticos y la libertad de prensa. El problema de España con respecto a esas internacionales consiste en que mientras existan, no tendrán amistades oficiales de verdad. La ayuda norteamericana se presta para cubrir una necesidad suya, pero de paso intentarán dominarnos, y esto es 10 que no hay que perder de vista. La ayuda se debe aprovechar, porque el comunismo es la amenaza más inmediata, pero con gran cuidado en no incurrir en concesiones peligrosas. De una agresión soviética, España no quedaría al margen, de modo que los acuerdos de 1953 ayudaron a poder afrontarla mejor, en todos los aspectos. Si dando facilidades a la defensa de Occidente mediante la cesión de unas bases, en la que se salvaba plenamente nuestra soberanía, se hallaba un medio para mejorar la dotación de los ejércitos y para aumentar el ritmo de desarrollo de la economía, al mismo tiempo se estaba trabajando por el desarrollo económico y la seguridad españolas. Sólo la pasión política o una cerrazón mental poco común, puede formular críticas a la aceptación española de estos Convenios. España, en cualquier caso es objetivo de la Unión Soviética, con bases y sin ellas, $y$ si con ellas podemos defendernos mejor, la ventaja de cederlas es evidente. El no hacerlo, sólo puede parecer bien a los necios o a los comunistas.

Más de siete años después de firmarse los convenios, Carrero todavía está pensando: con las bases, nos hemos hechos beligerantes oficiales contra el comunismo. Los Estados Unidos, deben por tanto ponernos en disposición de defendernos, de acuerdo con el artículo 1 del Convenio de Ayuda Militar. 
Por último, y como muestra de los últimos cambios en el entorno internacional de España, se pregunta: ¿nos han puesto los Estados Unidos en condiciones de defendernos de una agresión de la URSS? ¿Debe entenderse como tal una gresión de una potencia limitrofe armada y alentada por aquella, aunque se cubra con el disfraz de reivindicaciones territoriales absurdas? Si ambas preguntas tienen un no por respuesta, y si en la segunda, so pretexto de acción anticolonialista eso no se estima como previsto en los Convenios, quizás fuera más convenientes cancelarlos. Respecto de esta última afirmación, recibido efectivamente el no a las dos preguntas que se hacía Carrero, se puede decir que el precio político a pagar por prescindir el padrino político, era excesivamente elevado, y los días en que España era el Estado paria de Europa estaban demasiado próximos como para que el régimen se atreviera a dar un paso tan grave.

Toda la argumentación de Carrero Blanco sobre la utilidad para España de los convenios, descansa básicamente en una suposición y en un olvido. La primera, consiste en dar por hecho que España en cualquier caso seria un objetivo militar de la Unión Soviética en la eventualidad de declararse una guerra general. Lo cual bien podía ser posible y hasta probable, pero de lo que no hay duda es de que la instalación de bases aéreas y navales de utilización norteamericana automáticamente elevaba la cualificación del territorio español como objetivo militar soviético. Donde plausiblemente no había razones estratégicas para utilizar armas atómicas, las bases las hacían ineludibles en el caso de una guerra general. De todo lo cual resultaba que el régimen habia resuelto la necesidad de aumentar la seguridad de España aumentando simultáneamente el riesgo.

Que ello no escapaba a los responsables de los planes de defensa de España, se evidencia de la rapidez con que se urgió a los norteamericanos a la reubicación de las bases más próximas a las grandes ciudades, ante la conciencia del desastre que supondría el bombardeo atómico de Torrejón, Morón, Muntadas y Zaragoza. Ya durante el viaje de Martín Artajo a Estados Unidos en abril de 1956, éste plantea a Dulles la cuestión por primera vez, cuando ni siquiera estaba operativa la primera de las instalaciones militares de utilización conjunta. En diciembre de 1957, con motivo de la visita de Dulles a Madrid, la cuestión se volvió a plantear, afirmando el secretario de Estado que el hecho de que sea tan espantoso el efecto mortifero de la guerra nuclear hace que no sea tan importante el problema de la vecindad inmediata de las bases a las poblaciones. Franco, por su parte, insistía en el nivel alcanzado por las armas nucleares, por la aviación y los cohetes dirigidos, sugiriendo el examen del problema de la localizacion de las bases, y cuestiones relacionadas como la cooperación militar, el tráfico aéreo en las proximidades de las instalaciones militares, la conveniencia de dispersar las 
bases a lo largo del oleoducto Rota-Zaragoza, la posibilidad de utilizar los aeropuertos civiles como bases de emergencia y la posible utilización de instalaciones móviles para cohetes dirigidos. En abril de 1958, Dulles dirigió una carta a Franco en la que comunicaba que se había dado información a los militares españoles por los norteamericanos para aquietar las preocupaciones populares sobre la cuestión de la localización de las bases. Concluía todos vivimos hoy en peligro ${ }^{57}$. A esta carta, respondía el Jefe del Estado resaltando la vertiente política del problema de la ubicación de la bases, que se reflejaba en la creación de un Estado de opinión adverso a las mismas, al que convendria dar satisfacción en cuanto fuese posible, porque era una situación que los agentes y la propaganda comunista clandestinos estaban explotando en perjuicio de las relaciones bilaterales ${ }^{58}$. El resultado final de esta controversia fue que las bases permanecieron - permanecendonde inicialmente habian sido instaladas, evidenciándose una vez más la incapacidad que el régimen sufría para sobreponerse a decisiones del padrino político contrarias a sus propios intereses.

El olvido consistiría en prescindir de la comparación de los convenios que habia firmado España con los Estados Unidos con otros firmados por éste país. Desde luego que la nueva situación creada mejoraba las posibilidades defensivas españolas, pero aceptándose simultáneamente un trato discriminatorio al no recibirse las garantias que se daban a otros paises. Como es notorio que la incapacidad española para obtener una garantía defensiva tenía su origen el en carácter dictatorial del régimen, se puede afirmar que el propio régimen de Franco se convertía así en el mayor obstáculo para que la defensa de España fuera la más eficaz que podía ser, de la misma manera que, al ser rechazado por idénticas razones del Plan Marshall, el régimen de Franco se convertía en el mayor obstáculo para la recuperación económica española.

Las reacciones a que dio lugar la firma de los convenios, fueron naturalmente bien distintas en función de quién se tratase. Franco y Martín Artajo, en sus respectivos discursos a las Cortes con motivo de la remisión de los mismos para su aprobación, subrayaron la contribución que los convenios hacian a la defensa occidental, el respeto implícito a la ideología del régimen, y la plenitud y el éxito que alcanzaba la política exterior del régimen. Añadía el ministro que la ayuda económica que el pacto implicaba ofrecía unas enormes posibilidades de conseguir la reconstrucción económica y social, lo que

57 AmAE, D.G. Amér. R-12.028/1. Desarrollo de los Convenios hispano-norteamericanos de 1953. 12 de diciembre de 1961.

58 AMAE, D.G. Pol. Ext., R-5.790/3. Carta de Franco a John Foster Dulles. 28 de abril de 1958. 
contrasta con la que había de ser su opinión posterior. Del lado de la prensa controlada española, se desató una verdadera tormenta de alabanzas destinadas a Franco y a su sabia conducción de una política exterior española mundial. Entre tanto, otros españoles, los exiliados, advertían sobre el riesgo que corrian los Estados Unidos de enajenarse la buena voluntad del pueblo español, al concluir acuerdos que en la práctica lo que hacian era perpetuar la dictadura de Franco ${ }^{59}$. Por parte nortamericana, el recibimiento resultó ser ambigüo. Por un lado, el Departamento de Estado procuró restar importancia a los Convenios, subrayando las limitaciones de sus derivaciones políticas, e incidiendo en las puramente militares: no era una invitación hecha a España para ingresar en la OTAN, ni en la Comunidad Europea de Defensa, ni era un pacto de defensa mutua, ni se basaba en decisión alguna de hacer de los Pirineos la línea de defensa de Europa en caso de ataque soviético, ni era una aprobación del régimen de Franco; sí era puramente un acuerdo económico-militar que los estrategas norteamericanos consideraron altamente beneficioso para los Estados Unidos y Occidente, un producto de la era atómica que hacía más complejos los problemas de defensa, y una concesión a las llamadas «realidades» de la situación ${ }^{60}$. Por otro, Lequerica informaba desde Washington de la favorable acogida que había tenido en medios oficiales norteamericanos, entre miembros del Congreso y del Tribunal Supremo, añadiendo to irreal que sería esperar un lenguaje más entusiasta que el utilizado ${ }^{61}$. El agregado aéreo español añadía los comentarios recogidos entre el personal militar: en general mostraban una favorable acogida que no es normalmente entusiasta. A un nivel más general, se temía que el

59 Asi, alguien tan moderado como Salvador de Madariaga, en carta al editor del diario The New York Times, publicada el 17 de septiembre de 1953. La actitud de la opinión pública española con respecto a los Estados Unidos, en lo que puede ser conocido parece que tuvo un momento de entusiasmo inicial basado en la suposición de que la llegada de los norteamericanos iba a inundar de dólares la economía española. La comprobación de que su presencia no iba a cambiar mucho la situación del ciudadano medio, dio paso a la desilusión, que el curso de los años convirtió cuando menos en una cierta indisposición. Tras la muerte del general Franco, la libre difusión de la opinión política mostró hasta que punto estaba extendido el antiamericanismo -entendido como la oposición a la presencia de fuerzas militares norteamericanas en territorio español- de los españoles, que tuvo su expresión definitiva en el referéndum sobre la permanencia de España en la OTAN, en 1986, en el que la opción opuesta a ella, respaldada por todas las organizaciones politicas a la izquierda del PSOE —e importantes corrientes de opinión de ese partido--, obtuvo más de nueve millones de votos, casi el $40 \%$ de los emitidos, ello a pesar de la intensa campaña politica favorable a la permanencia encabezada por el propio gobierno socialista.

60 AMAE, D.G. Amér., R-3.187/26. OID, nota para la superioridad. 30 de septiembre de 1953. Nota para el Sr. Ministro, 1 de octubre de 1953.

61 PG-AJE, leg. 18. Telegrama s/n DVEP. 1 de octubre de 1953. Por cierto que en esta oca sión Lequerica se deja llevar por el entusiasmo al afirmar: Ahi está el hecho de una efectiva alianza (llamesela como se la llame) y amistad con Estados Unidos en todo su valor. 
pacto fuera una fuente de nuevos y cuantiosos gastos para el contribuyente norteamericano, siendo evidente que la idea de la aproximación a España aún no es popular, aunque existen cada vez más indicios de haber dejado de ser, como ha sido desde la pasada guerra, tremendamente impopular ${ }^{62}$. También en Estados Unidos, y entre la prensa norteamericana de mayor difusión, solamente The New York Times mostraba alguna reserva, manifestándose más o menos positivamente el resto de los periódicos.

La opinión pública, pronto habría de tener alguna indicación en el sentido de que los Convenios hechos públicos estaban completados por otras disposiciones secretas. A lo largo de su visita a España, el 3 de noviembre de 1953 Harold E. Talbott, Secretario de la Fuerza Aérea, declara que los EEUU podrían almacenar armamento atómico en las bases españolas, afirmaciones que se ven obligados a rectificar John Foster Dulles como Secretario de Estado y Charles E. Wilson como Secretaro de Defensa. Por parte española, no hay reacción oficial, salvo una telegrama de Eduardo Propper del Callejón (encargado de negocios de España en Washington) al ministerio aludiendo a la descoordinación de las declaraciones hechas por los funcionarios norteamericanos. Dulles, en evidente falta a la verdad, y ante preguntas formuladas por periodistas, afirma que existen "acuerdos subsidiarios" sobre "aspectos técnicos del Acuerdo", que no son de carácter político, como lo son los acuerdos hechos públicos ${ }^{63}$. En el fondo de esta implícita desautorización de Talbott, lo que aparentemente más debía de temer el secretario de Estado era que algo pudiera entorpecer la ratificación por Francia del acuerdo para la creación de un ejército europeo, más que la reacción de la opinión pública.

\section{CONCLUSION}

La evolución de las relaciones hispano-norteamericanos durante la Administración Eisenhower, siguió la tendencia ya iniciada durante la de Truman, en el sentido de hacerlas progresivamente más estrechas, y en un proceso que vino a culminar con la firma de los Convenios de 1953.

Esto no debe sin embargo ocultar el hecho fundamental de que tal aproximación tenía unos límites que el curso de los acontecimientos en la esfera internacional se encargarian de poner de manifiesto. En este sentido,

\footnotetext{
62 AMAE, D.G., Amér., R-3.177/10. Despacho no 86 del agregado aéreo en Washington. 5 de octubre de 1953.

63 AmAE, D.G. Amér., R-3.187/25.
} 
fue la propia experiencia la que puso en evidencia para el régimen español hasta donde podía contar con el apoyo diplomático del "padrino político" para resolver los más urgentes problemas que se le venían planteando, contrastando inevitablemente con el que de hecho obtenían otros países que si eran auténticos aliados de los Estados Unidos. Lo cual nos permite comprobar a su vez que los Convenios que había firmado España tenían la evidente condición de "matrimonio de conveniencia", centrados como estaban en consideraciones eminentemente estratégicas. $Y$ es que seguramente tampoco podía ser de otra manera. Lo esencial que vinculaba al gobierno de España y al de los Estados Unidos, era la cuestión puramente negativa de la común aversión a la Unión Soviética y al comunismo, y no mucho más. Siendo esto así, no resultaba sencillo que la proclamada amistad mutuamente profesada fuera muy profunda, ni que llegara muy lejos. Del lado español, por lo menos, ya se ha visto como existía plena conciencia de las consecuencias que cabía esperar tuviera la radical divergencia de principios que inspiraban a uno y otros sistemas políticos.

En otro orden de cosas, la relativa rapidez con la que el gobierno español demandó del de los Estados Unidos la revisión de cuestiones esenciales relacionadas con los Convenios de 1953, aparece como un significativo indicio de que el régimen consideraba primordial ante todo la obtención del "seguro de vida» que el pacto implícitamente conllevaba. Por esa razón, solamente después de cobrados los dividendos políticos que los convenios ofrecian, se podía pensar en enmenda la situación creada por la aceptación inicial de unas condiciones que bien pronto, si no desde el principio mismo, se sabían plenamente insatisfactorias para los intereses del país - distinguiéndose aqui estos de los del régimen- El problema que se planteaba a continuación, era que la parte norteamericana no iba en modo alguno a ser receptiva a la rectificación de por lo menos una de las fundamentales, la reubicación de las bases más próximas a las grandes ciudades. La consecuencia final, es bien obvia: varias décadas con una espada de Damocles nuclear sobre la cabeza de millones de españoles. Porque resulta difícil admitir que en el momento de negociarse los Convenios no se advirtiese el cuando menos potencial riesgo que suponía instalar seguros blancos nucleares en las proximidades de las mayores ciudades españolas. Franco aludiría en 1958, como se ha visto, a los progresos hechos por los armamentos nucleares, pero mal se puede explicar que cinco años antes, casi simultáneamente a la explosión de la primera bomba de hidrógeno soviética, no se tuviera presente que no estaba lejos el día en que, por medio de aviones o de misiles, estuviese en condiciones de alcanzar objetivos en la Península Ibérica. A no ser que esa previsión se soslayara en benefició de otras consideraciones, que no 
podian ser más que política o de imagen, y en la línea de lo que se viene afirmando.

Conseguida la seguridad de la amistad estable de los Estados Unidos, y conscientes los responsables de la política exterior española de que el valor del régimen para los norteamericanos estaba en relación proporcional directa con el valor que tuvieran las instalaciones militares conjuntas, el gobierno español se esforzó en todo momento en subrayar la amenaza soviética. En este sentido, la tensión internacional beneficiaba al régimen por partida doble: de un lado, le permitía fortalecer su posición internacional, poníendole más a resguardo si cabe de cambios indeseables; de otro, le permitía insistir con más fundamento en la necesidad de aumentar la ayuda norteamericana a España. Así las cosas, da la impresión de que los sucesivos gobiernos de Franco buscaban la solución de los graves problemas que tenía planteados la economía española, y los que se podrían derivar de ellos para su estabilidad, en la explotación de la situación internacional y de la guerra fría, cuya agudización significaba la perspectiva de medrar en medio de la adversidad general que significaba una guerra fría en trance de alcanzar límites extremos, hecho que caracteriza al régimen en alguno de sus aspectos más profundos.

Todo lo anterior, sumado a la profunda hostilidad albergada hacia la Unión Soviética, explica que los esfuerzos internacionales en pro de la paz emprendidos en la década de los cincuenta, fueran recibidos con muchas reservas. Una dictadura militar, y más una dictadura militar surgida de una guerra civil como la española, difícilmente podía tener la paz como divisa. Existía, eso sí, la paz en el interior de España, cuyos logros la propaganda se encargaba de difundir, pero esa era de una condición bien distinta. Que la paz significara coexistencia con los países comunistas de Europa del Este, automáticamente la hacía sospechosa. Muy al contrario, el régimen abogaba por una "verdadera paz", que pasaba por supuesto por la liquidación del Estado soviético. En cuanto a los medios para alcanzarla, había pocas dudas: ahí estaba el plan para suministrar armas ligeras españolas, transportadas por aviones del SAC, a los sublevados de Hungria en 1955.

Todo lo cual, permite preguntarse si acaso las ya lejanas, en 1953, denuncias en la ONU del delegado polaco acerca de la amenaza para la paz que constituia el régimen español, no estarian más fundadas de lo que generalmente se pensó. Amenaza tal vez no inmediata, pero sí de una potencialidad que por fortuna nunca tuvo la ocasión de materializar. 